Aus der Abteilung Neurologie (Prof. Dr. med. M. Bähr)

im Zentrum Neurologische Medizin

der Medizinischen Fakultät der Universität Göttingen

\title{
Molekulare Zellstressmechanismen bei der hereditären Einschlusskörpermyopathie
}

\section{Inaugural-Dissertation}

\author{
zur Erlangung des Doktorgrades \\ der Medizinischen Fakultät \\ der Georg-August-Universität zu Göttingen \\ vorgelegt von \\ Charlotte Viola Fischer \\ aus Velbert \\ Göttingen 2011
}


Dekan: Prof. Dr. med. C. Frömmel

I. Berichterstatter: PD Dr. med. J. Schmidt

II. Berichterstatter/in: Prof. Dr. med. E. Wilichowski

III. Berichterstatter/in:

Tag der mündlichen Prüfung: 05.06.2012 


\section{Inhaltsverzeichnis}

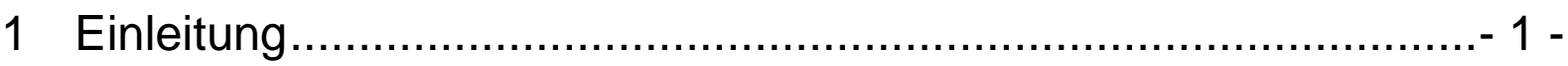

1.1 Hereditäre Einschlusskörpermyopathie .................................... 1 -

1.1.1 Geschichte ...................................................................... 1 -

1.1.2 Symptomatik und Verlauf ....................................................... 2 -

1.1.3 Histopathologie und Pathophysiologie..................................... 4 -

1.1.4 Diagnostik und Therapie ................................................... 7 -

1.2 Marker für Proteinakkumulation, Degeneration und Regeneration,

Entzündung und Zellstress ..................................................... 8 -

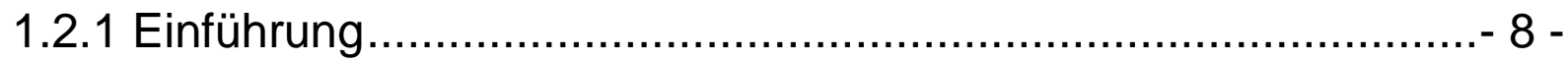

1.2.2 Marker für Proteinakkumulation ............................................ 8 -

1.2.2.1 Amyloid Precursor Protein (APP) und $\beta$-Amyloid .................... 8 -

1.2.2.2 Ubiquitin ........................................................................... 9 -

1.2.2.3 Neurofilamente/phosphoryliertes Tau ................................... 9 -

1.2.3 Marker für Degeneration und Regeneration ............................. 9 -

1.2.3.1 Desmin ............................................................................. 9 -

1.2.3.2 Neuronal Cell Adhesion Molecule (NCAM) ........................... 10 -

1.2.4 Zellstress-assoziierte Marker................................................. 10 -

1.2.4.1 aB-Crystallin........................................................... 10 -

1.2.4.2 Major Histocompatibility Complex I (MHC-I) ......................... 10 -

1.2.4.3 Induzierbare Stickoxidsynthase (iNOS) ............................. 11 -

1.2 .5 Zytokine ........................................................................... 11 -

1.2.5.1 Interleukin (IL) 1 $\beta$, IL 6 und Interferon (IFN) Y ..................... 11 -

1.2.5.2 Tumor-Nekrose-Faktor (TNF) $\alpha$ und transforming growth factor

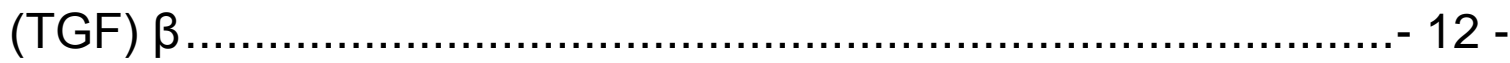

1.2.5.3 Monokine induced by gamma-Interferon (MIG) ................... 13 -

1.2.5.4 Makrophagen-Inflammatorisches Protein (MIP) $1 \alpha$ und $1 \beta-13$ -

2 Ziele der Arbeit .................................................................. 14 -

3 Material und Methoden ........................................................ 16 - 
3.1 Immunbiologische Materialien und Methoden $-16-$

3.1.1 Patienten und Kontrollen $-16-$

3.1.2 Hämalaun- und Eosin-Färbung ..................................... 17 -

3.1.3 Immunhistochemische Färbungen....................................... 18 -

3.1.4 Fluoreszenz-mikroskopische Analyse ................................ 19 -

3.2 Molekularbiologische Methoden und Materialien ........................ 20 -

3.2.1 RNA-Extraktion aus Gewebe........................................... 20 -

3.2.2 cDNA-Synthese ......................................................... 20 -

3.2.3 Quantitative (real-time) Polymerase-Kettenreaktion ................. 21 -

3.3 Statistische Methoden ......................................................... 22 -

4 Ergebnisse.............................................................. 23 -

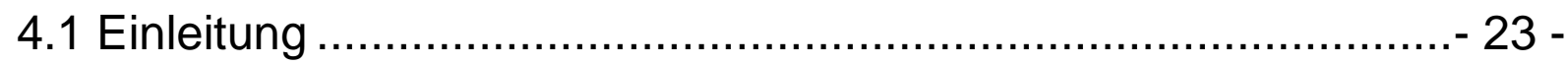

4.2 mRNA-Expression von Markern für Entzündung, Zellstress und

Proteinakkumulation bei der hIBM ....................................... 23 -

4.3 mRNA-Expression von Markern für Entzündung, Zellstress und

Proteinakkumulation im Vergleich zu Kontrollen ......................... 25 -

4.4 Korrelation der mRNA-Expression bei hIBM von Markern für

Proteinakkumulation und Zellstress mit pro-inflammatorischen

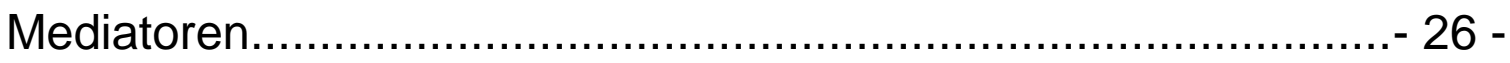

4.5 Quantitative Analyse seriell gefärbter Schnitte von Patienten mit

hIBM: Marker für Proteinakkumulation, Zellstress und

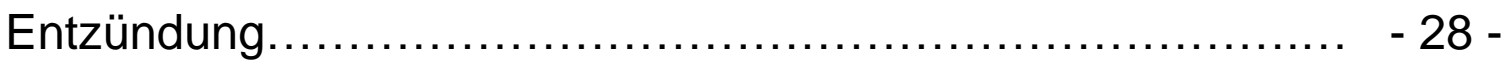

4.6 Korrelation der Proteinexpression von degenerativen, pro-

inflammatorischen und Zellstress-assoziierten Markern................ 31 -

4.7 Quantitative, lichtmikroskopische Analyse der H\&E-Färbung ....... 32 -

4.8 Expression von Markern für Proteinakkumulation, Entzündung und

Zellstress in normal erscheinenden Muskelfasern von hIBM-Patienten -35 -

4.9 Geschlechtsspezifische Analyse in der Expression von Markern für

Degeneration, Entzündung und Zellstress bei hIBM $-38-$

4.9.1 Einleitung $-38-$

4.9.2 Geschlechtsspezifische mRNA-Expression $-38-$ 
4.9.3 Unterschiede der Proteinexpression

4.9.4 Geschlechtsspezifische Analyse morphologischer Auffälligkeiten im hIBM-Muskel $-40-$

5 Diskussion $41-$

5.1 aB-Crystallin und iNOS als frühe pathogenetische Indikatoren bei der hIBM -41 -

5.2 Pro-inflammatorische Pathomechanismen bei der hIBM $-42-$

5.3 Einfluss von aB-Crystallin auf die Morphologie des Muskels von Patienten mit hIBM $-43-$

5.4 Einfluss des Geschlechts auf die Muskelpathologie bei der hIBM- 45

6 Zusammenfassung 47

7 Literaturverzeichnis. 49 


\section{Abkürzungsverzeichnis}

$\begin{array}{ll}\text { AB } & \text { B-Amyloid } \\ \text { APP } & \text { Amyloid Precursor Protein } \\ \text { BSA } & \text { Rinderserumalbumin } \\ \text { CDNA } & \text { komplementäre DNA } \\ \text { CK } & \text { Creatin-Kinase } \\ \text { DAPI } & \text { 4'6-Diamidin-2-phenylindol } \\ \text { DMRV } & \text { distal myopathy with rimmed vacuoles } \\ \text { GAPDH } & \text { Glycerinaldehyd-3-Phosphat-Dehydrogenase } \\ \text { GNE } & \text { UDP-N-acetylglucosamine 2-epimerase/N- } \\ \text { acetylmannosaminekinase } \\ \text { H\&E } & \text { Hämalaun und Eosin } \\ \text { hIBM } & \text { hereditäre Einschlusskörpermyopathie } \\ \text { IBM } & \text { inclusion body myopathy/myositis } \\ \text { IFN } & \text { Interferon } \\ \text { IL } & \text { Interleukin } \\ \text { iNOS } & \text { induzierbare Stickoxidsynthase } \\ \text { MHC } & \text { major histocompatibility complex } \\ \text { MIG } & \text { monokine induced by gamma-interferon } \\ \text { MIP } & \text { Makrophagen-Inflammatorisches Protein } \\ \text { mRNA } & \text { messenger ribonucleic acid } \\ \text { MW } & \text { Mittelwert } \\ \text { NCAM } & \text { Neuronales Zell Adhäsions Molekül } \\ \text { NEP } & \text { Neprilysin } \\ \text { PBS } & \text { Phosphat-gepufferte Salzlösung } \\ & \end{array}$


PFA Paraformaldehyd

PSA-NCAM poly-sialated Neuronales Zell Adhäsions Molekül

ROX Carboxy-X-Rhodamin

RT-PCR real-time- Polymerasekettenreaktion

SD Standardabweichung

sIBM sporadische Einschlusskörpermyopathie

TGF transforming growth factor

TNF Tumor-Nekrose Faktor

UBB Ubiquitin 


\section{Einleitung}

\subsection{Hereditäre Einschlusskörpermyopathie}

Die Einschlusskörpermyopathie (inclusion body myopathy/myostitis, IBM) ist eine Erkrankung des Skelettmuskels. Der Begriff wurde erstmals 1971 eingeführt [Yunis und Samaha 1971]. Es gibt eine sporadische Form (sIBM) und eine hereditäre (hIBM).

Die hIBM, auch bekannt als distal myopathy with rimmed vacuoles (DMRV) oder Nonaka Disease, gilt als nicht-entzündliche Erkrankung [Mitrani-Rosenbaum et al. 1996], deren Pathogenese genetischer Natur ist. Sie ist Gegenstand dieser Dissertation.

\subsubsection{Geschichte}

Bereits 1981 wurde erstmals von Nonaka et al. eine familiäre distal betonte Myopathie mit intrazellulären Vakuolen und lamellärer Körperbildung in den Muskelfasern bei zwei japanischen Familien beschrieben. Die Entdeckung gab dieser neuartigen Erkrankung dann auch den Namen: distal myopathy with rimmed vacuoles (DMRV), zum Teil wurde sie aber auch nach dem Entdecker als Nonaka Disease benannt.

1984 beschrieben Argov und Yarom eine ähnliche distale Myopathie unter iranischen Juden mit relativem Ausschluss der Quadrizeps-Muskulatur auch im weiteren Verlauf der Erkrankung. 1993 prägten Askanas und Engel den Begriff „hereditäre Einschlusskörpermyopathie“ für diese Erkrankung. Es wurde bewusst der Begriff "Myopathie“ anstelle von "Myositis“ gewählt, da ein entzündlicher Prozess in der hereditären Variante bis dahin nicht beschrieben worden ist [Askanas und Engel, 1993] und dies der Begriff „Myositis“ suggerieren würde. 1996 wurde dann der Genlocus für die hereditäre Einschlusskörpermyopathie auf Chromosom 9p1-q1 entdeckt [Mitrani-Rosenbaum et al. 1996]. 2001 konnte klar beschrieben werden, dass eine Mutation im UDP-N-acetylglucosamine 2-epimerase/ $\mathrm{N}$-acetylmannosamine kinase-Gen (kurz GNE-Gen) für die Entstehung des klinischen Phänotyps verantwortlich ist [Eisenberg et al. 2001]. 2002 wurde bewiesen, dass die DMRV und 
die hIBM die gleiche Erkrankung sind. Beide Erkrankungen weisen Mutationen im GNE-Gen als grundlegende Pathogenese auf [Nishino et al. 2002]. Allerdings weisen die verschiedenen Formen der Erkrankung auch ein unterschiedliches Mutationsspektrum auf, was auch die variable Ausprägung der Symptomatik erklärt (siehe unten). Bis heute sind über 50 unterschiedliche autosomal rezessiv und autosomal dominant verlaufende Mutationen im GNE-Gen bei Patienten mit hIBM/DMRV bekannt (Punkt-Mutationen, Deletionen und Insertionen) [Broccolini et al. 2009]. Am verbreitesten sind die Punktmutation p.M712T bei der hereditären Einschlusskörpermyopathie, vorwiegend bei persischen Juden und Familien aus dem mittleren Osten [Eisenberg et al. 2001], und die missense-Mutation p.V572L, die bei japanischen Patienten mit DMRV entdeckt worden ist [Arai et al. 2002]. 2007 gelang es dann auch, ein Maus-Modell für die GNE-D176V-Mutation zu generieren [Malicdan et al. 2007], welches einen klinischen Phänotyp ähnlich der hIBM entwickelt.

\subsubsection{Symptomatik und Verlauf}

Die hereditäre Einschlusskörpermyopathie ist eine chronisch-progressive Muskelerkrankung, die zu schwerer Muskelschwäche und Muskelatrophie sowohl distaler als auch proximaler Muskeln führt. Der Beginn der Erkrankung liegt meist zwischen dem 15. bis 40. Lebensjahr mit einem mittleren Erkrankungsalter von 26 Jahren [Nonaka 1999]. Der klinische Phänotyp von Patienten mit hIBM/DMRV zeigt eine erhebliche Varianz an Ausprägung und Muskel-Befallsmuster. In den meisten Fällen ist der M.tibialis anterior der erste betroffene Muskel. Die Symptomatik entspricht dann dem Befallsmuster der Erkrankung, wie zum Beispiel Gehschwierigkeiten und Probleme beim Treppensteigen bei Befall des M. tibialis anterior [Nonaka et al. 2005]. Es können aber auch andere Muskeln zuerst von der Erkrankung befallen werden, wie zum Beispiel die Finger- und Handmuskulatur, was sich dann klinisch durch feinmotorische Schwierigkeiten darstellt [Nishino et al. 2005]. Insgesamt ist es eine langsam forstschreitende Erkrankung, deren Verlauf schwer vorhersagbar ist, die nach drei bis zweiundzwanzig Jahren, im Durchschnitt nach 12 Jahren, zu schwerer Behinderung führt [Nishino et al. 2005, Nonaka 1999]. Fast in allen Fällen ist der M. quadriceps an dem Erkrankungsbild auch im 
fortgeschrittenen Stadium nicht beteiligt, was als einzigartig für diese Erkrankung beschrieben wird [Sadeh et al. 1993] und weshalb sie auch als Quadriceps sparing myopathy bezeichnet werden kann. Allerdings zeigte eine Studie von Ultraschalluntersuchungen bei hIBM-Patienten 2007 eine sonographische Beteiligung des M. rectus femoris bei fast allen Patienten [Adler et al. 2008]. Auch Herz- und Atemmuskulatur sind in der Regel nicht involviert [Nonaka et al. 2005], besonders die Herzfunktion sollte aber dennoch überwacht werden, da eine erhöhte Anzahl an Herzrhythmusstörungen bis hin zu plötzlichem Herztod bei hIBM-Patienten beobachtet wurde [Nishino et al. 2005]. Eine genauere Erklärung hierfür gibt es bislang nicht. Es gibt auch einzelne Berichte über Patienten mit der Mutation im GNE-Gen, die aber nie einen klinischen Phänotyp entwickelt haben [Nishino et al. 2005], ebenso wie Berichte über Patienten mit autosomal rezessiver IBM, aber ohne Mutation im GNE-Gen [Di Blasi et al. 2000], was ebenfalls bisher nicht erklärt ist. Eine Erhöhung der Serum-Creatin-Kinase (CK) im Krankheitsverlauf als Marker für Muskelschädigung und Muskelerkrankung ist nicht oder nur gering zu sehen.

Es gibt auch andere Formen der hereditären Einschlusskörpermyopathie, die unter verschiedenen Namen beschrieben und jeweils einen eigenen klinischen Verlauf und verschiedene ethnische Verteilungsmuster aufweisen [Eisenberg et al. 2003]. Ein Beispiel ist die "Welander Myopathie“, eine dominant vererbte Erkrankung mit einer Mutation auf Chromosom 2p13, beschrieben in Skandinavien, vorwiegend in den mittleren und nördlichen Teilen von Schweden und Teilen Finnlands [Ahlberg et al. 1999]. Sie zeigt eine ähnliche Muskelpathologie wie die hIBM und ebenfalls als Erstes einen Befall der distalen Hand- und Fußmuskulatur. Der Erkrankungsbeginn ist allerdings im Mittel deutlich später.

Ein weiteres Beispiel für eine Unterform der hereditären Einschlusskörpermyopathie ist die autosomal dominant verlaufende Einschlusskörpermyopathie Typ 3. Diese Myopathie, beschrieben bei einer schwedischen Familie, manifestiert sich bereits bei Geburt durch Kontrakturen und ist im Verlauf meist milde. Allerdings verläuft sie langsam progressiv über 30 bis 50 Jahre [Martinsson et al. 2000]. Bei dieser Erkrankung wurde eine missense-Mutation auf Chromosom 17p13.1, dem Gen für die schwere Kette des Myosins, entdeckt. Die Muskelfasern zeigen histopathologische Kennzeichen wie atrophe Fasern und Vakuolen, die belegen, 
dass es sich auch hier um eine Variante der hIBM/DMRV handelt [Eisenberg et al. 2001].

\subsubsection{Histopathologie und Pathophysiologie}

In Muskelfasern von hIBM-Patienten finden sich charakteristische, histopathologische Veränderungen. Dazu gehören eine erhebliche Varianz bei der Größe der einzelnen Muskelfasern und die Zentralisierung von Kernen als Ausdruck myopathischer Veränderungen. Einige Muskelfasern enthalten Vakuolen, die unter dem Elektronenmikroskop phosphorylierte Neurofilamente als Inhalt zeigen. Phosphorylierte Neurofilamente kommen allerdings auch im Zytoplasma Vakuolenfreier Muskelfasern vor. Zudem gibt es im hIBM-Muskel auch immer eine erhebliche Anzahl atropher Fasern. Bei einer weiteren immunohistochemischen Untersuchung zeigt sich eine abnormale Akkumulation von APP und seinem toxischen Produkt $\beta$ Amyloid und des Antikörpers SMI-31 als Indikator für hyperphosphoryliertes Tau [Broccolini et al. 2009] [siehe Abbildung 1]. Auch wenn in einzelnen Fällen inflammatorische Infiltrate im hIBM-Muskel beschrieben wurden [Yabe et al.2003], ist gerade das Fehlen von Entzündung im Muskel der Unterschied zur slBM [Askanas und Engel 1998]. 


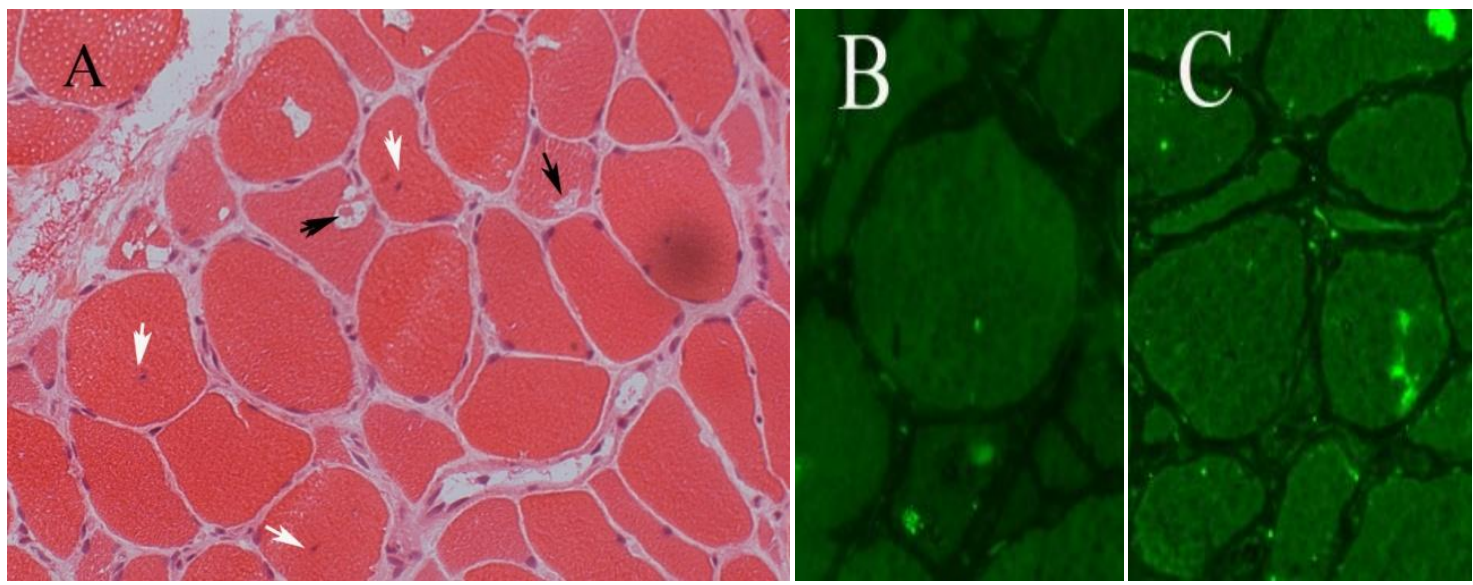

Abb.1: Histopathologische Charakteristika im hIBM-Muskelgewebe A) zeigt eine H\&EFärbung mit erheblicher Größenvariation der Muskelfasern, sowie Fasern mit Vakuolen (schwarze Pfeile) und Fasern mit internalisierten Nuclei (weiße Pfeile), (die Aufnahme wurde mit einem 20er Objektiv angefertigt), in Abbildung B) ist eine Muskelfaser positiv für SMI-31 in der Immunhistochemischen Färbung dargestellt, in Abbildung $\mathbf{C}$ ) zeigen sich Muskelfasern positiv für $\beta$-Amyloid.

Die Pathophysiologie der hIBM ist sehr komplex und bislang nicht genau verstanden. Zu Grunde liegt eine Mutation im GNE-Gen, einem bifunktionalen Schlüsselenzym für die Synthese von Sialinsäure. Das Enzym katalysiert zwei initiale Schritte in der Biosynthese der Sialinsäure; zunächst die Umwandlung von UDP-GlcNAc zu ManNAc und dann die Phosphorylierung zu ManNAc-6-Phosphat. Dieses wird dann von weiteren Enzymen in mehreren Schritten zu Sialinsäure umgewandelt [Keppler et al. 1999]. Mutationen können sowohl die Epimerase- als auch die Kinase-Domäne betreffen, wobei diese dann die andere Domäne in ihrer Funktion nicht mit einschränkt [Keppler et al. 1999]. Durch die Mutationen ist die Enzymaktivität des GNE-Enzyms um bis zu 68,2\% reduziert [Noguchi et al. 2004].

Sialinsäure liegt am Glykolipid- und Oligosaccharid-Ende von Glykoproteinen auf Zelloberflächen und ist für deren zelluläre Formation, Migration, Interaktion und Stabilität verantwortlich. Bei hIBM-Patienten wurde bislang keine Null-Mutation entdeckt, sondern lediglich Mutationen, die eine Restenzymaktivität im Muskel nahelegen [Malicdan et al. 2007]. Im Mausmodell zeigte sich, dass ein kompletter Ausfall der GNE-Funktion für den Embryo letal ist [Schwarzkopf et al. 2002].

Bei hIBM-Patienten wurde als Folge der Mutation im GNE-Gen eine geringere Aktivität der Epimerase-Aktivität in Lymphoblasten und Leukozyten-Zelllinien beobachtet [Hinderlich et al. 2004]. An Myotuben von Muskelbiopsieproben von 
hIBM-Patienten konnte gezeigt werden, dass diese geringer sialisiert sind [Malicdan et al. 2007]. Auch eine Hyposialylierung von Glykoproteinen bei hIBM-Patienten im Skelettmuskel konnte beobachtet werden [Saito et al. 2004]. Allerdings wurde auch gezeigt, dass die Erkrankung nicht zu einer generellen Hyposialylierung der Muskelzellen ex vivo führt [Salama et al. 2005]. Auch wurden keine erniedrigten Serumwerte für Sialinsäure bei hIBM-Patienten oder eine geringere Sialylierung anderer Organe außerhalb des Muskels gefunden.

Publikationen über eine mögliche Hyposialylierung der Muskelfasern bei hIBMPatienten sind sehr widersprüchlich. Dennoch konnte gezeigt werden, dass das hochphosphorylierte Neuronale Zell-Adhäsions-Molekül (Poly-Sialated (PSA) NCAM) auch bei Patienten, die keine Hyposialylierung im Muskelgewebe zeigen, eine geringere Sialylierung von PSA-NCAM im Vergleich zu anderen Myopathien aufweist [Ricci et al. 2006]. Eine weitere Theorie zu möglichen Pathomechanismen unterstützt die Beobachtung, dass ebenfalls Neprilysin (NEP) im hIBM-Muskel hyposialisiert ist. NEP ist eine Metallopeptidase, welche $\beta$-Amyloid spalten kann. Die Hyposialylierung reduziert sowohl seine Expression als auch die Enzymaktivität und ist assoziiert mit einer erhöhten $\beta$-Amyloid-Akkumulation in der Muskelfaser [Broccolini et al. 2008]. Des Weiteren wird diskutiert, ob eine Veränderung mitochondrialer Prozesse durch die GNE-Mutation eine Rolle bei der Pathologie der hIBM haben könnte [Eisenberg et al. 2008]. Die frühere Theorie, dass die Hyposialylierung von a-Dystroglykan, einem Verbindungsprotein zwischen extrazellulärer Matrix und Zytoskelett, einen wesentlichen Einfluss auf die Ausbildung des Krankheitsbildes hat, ist inzwischen verworfen worden [Broccolini et al. 2005].

Der genaue Mechanismus zwischen der Mutation und der Entstehung der Muskelpathologie ist somit bisher ungeklärt. 


\subsubsection{Diagnostik und Therapie}

Kriterien für die Diagnosestellung der hIBM beinhalten 1. das Auftreten einer distal betonten Muskelschwäche, 2. eine Nichtbeteiligung der Quadrizeps-Muskulatur auch in weit fortgeschrittenen Stadien der Erkrankung, 3. früher Beginn der Erkrankung vor dem vierten Lebensjahrzehnt, 4. keine oder nur minimale Erhöhung der SerumCreatin-Kinase, 5. histologischer Nachweis von Vakuolen in Muskelfasern ohne Hinweise auf Entzündung und 6. tubulofilamentäre Einschlüsse in der Muskelfaser bei der elektronenmikroskopischen Untersuchung [Jay et al. 2009]. Eine positive Familienanamnese für Muskelschwäche ist nicht obligat [Jay et al. 2009]. Auch die intrazelluläre Akkumulation von $\beta$-Amyloid im Muskel, sowie die Ablagerung von Prion-Proteinen, phosphoryliertem Tau und weiteren Proteinen in Muskelfasern mit Vakuolen sind wichtige Hinweise für die Diagnosestellung „hlBM“ [Griggs et al. 1995].

Bis heute ist keine effektive Behandlung der hereditären Einschlusskörpermyopathie verfügbar, um den Verlauf der Erkrankung aufzuhalten. Da gezeigt werden konnte, dass hIBM-Muskelzellen, die mit Sialinsäure und/oder seinem Vorläufermolekül behandelt wurden, einen normalen Sialylierungsstatus bekamen [Noguchi et al. 2004], wurde die Gabe von Sialinsäure auch als mögliche Therapieoption diskutiert. Eine Studie an Patienten zeigte dann zwar, dass es durch die kurzzeitige Gabe von intravenösen Immunglobulinen, welche ebenfalls Sialinsäure enthalten, zu einer vorrübergehenden Verbesserung der klinischen Symptomatik kommt, aber die Sialylierung im Gewebe und die Ausbildung der typischen Muskelpathologie davon unbeeinflusst bleibt [Sparks et al. 2007]. In einer Einzelfallstudie konnte 2009 bei einer Patientin mit weit fortgeschrittener hIBM ein Therapieversuch mit intramuskulärer Injektion von GNE mittels Liposomen unternommen werden, der bei der Patientin lokoregional zu einer deutlichen Verbesserung der Muskelkraft, einer transienten Erhöhung der GNE-Expression und einer Erhöhung des Sialylierungslevels im Muskel führte [Nemunaitis et al. 2010]. Dies ist möglicherweise ein Ansatz einer effektiven Therapie der hIBM für die Zukunft. 


\subsection{Marker für Proteinakkumulation, Degeneration und Regeneration, Entzündung und Zellstress}

\subsubsection{Einführung}

In dieser Dissertation wurden Muskelbiospie-Proben von Patienten mit hIBM bezüglich der Expression verschiedener Marker für Proteinakkumulation, Degeneration/Regeneration, Entzündung und Zellstress untersucht. Diese werden im Folgenden kurz vorgestellt.

\subsubsection{Marker für Proteinakkumulation}

\subsubsection{Amyloid Precursor Protein (APP) und $\beta$-Amyloid}

Amyloid Precursor Protein (APP) ist ein transmembranöses zelloberflächliches Glykoprotein, durch dessen Prozessierung $\beta$-Amyloid gebildet werden kann. Es kann transmembranös und im Golgi-Apparat oder endoplasmatischen Retikulum lokalisiert sein und nimmt an vielen verschiedenen zellulären Prozessen wie z.B. intrazelluläre Signalgebung, Membran-zu-Kern-Kommunikation, Zelladhäsion und Neuroproliferation teil. APP kommt ubiquitär im Körper vor und liegt gewebsspezifisch in drei verschiedenen Isoformen vor, die durch alternatives Splicing der prä-mRNA entstehen und danach weiter postranslational prozessiert werden. Die spezifische neuronale Isoform $\mathrm{APP}_{695}$ liegt ebenfalls als transmembranöses Molekül vor und kann proteolytisch gespalten werden. Durch $\beta$ und $\gamma$-Sekretase entsteht das Spaltprodukt $\beta$-Amyloid mit seinen häufigsten Isoformen $A \beta_{1-40}$ und $A \beta_{1-42}$, deren Oligomerisierung zelltoxisch ist [Turner et al. 2003]. Im IBM-Muskel kommen die $\beta$-Sekretasen BACE1 und BACE2 in Fasern mit Vakuolen vor und ko-lokalisieren mit $\beta$-Amyloid. Es können erhöhte BACE-ProteinWerte gemessen werden, welche zu einer stark erhöhten $A \beta_{1-42}$-Produktion im IBMMuskel führen [Vattemi et al. 2003, Nogalska et al. 2010]. Es wird angenommen, dass die dadurch entstehende $\beta$-Amyloid-Akkumulation in Muskelfasern der hIBM einen bedeutenden Anteil an der Entstehung der Muskelpathologie hat und sie dadurch zur Degeneration des Muskels und zu Muskelschwäche führt [Jayaraman et al. 2008]. Zudem wird angenommen, dass $\beta$-Amyloid unter anderem die 
Proteasomaktivität mindert und dadurch die Ablagerung von Proteinen in der Zelle fördert [Askanas et al. 2009].

\subsubsection{Ubiquitin}

Ubiquitin ist ein kleines, durch Zellstress induziertes Protein, welches unter anderem für die Prozessierung von Proteinen in Proteasomen verantwortlich ist. Studien haben gezeigt, dass Ubiquitin ein Teil von Einschlusskörperchen bei neurodegenerativen Erkrankungen ist [Manetto et al. 1988] und dass auch vakuolisierte Muskelfasern im IBM-Muskel Ubiquitin enthalten [Askanas et al. 1991]. Es konnte zudem gezeigt werden, dass eine abnormale Akkumulation von Ubiquitin im IBM-Muskel mit der Akkumulation von $\beta$-Amyloid gemeinsam auftritt [Askanas et al. 1993]. Auch mutiertes Ubiquitin $\left(\mathrm{UBB}^{+1}\right)$ aggregiert im slBM-Muskel, wo es zum einen an einer Proteasom-Inhibition beteiligt ist und zum anderen die Aggregation von $\beta$-Amyloid und phosphoryliertem Tau beeinflussen kann [Fratta et al. 2004].

\subsubsection{Neurofilamente/phosphoryliertes Tau}

Das Tau-Protein ist ein Zellprotein, welches an Mikrotubuli bindet und somit deren Zusammenbau reguliert. Wie auch bei der sIBM akkumuliert phosphoryliertes Tau in den Muskelfasern von hIBM-Patienten. Hier kommt es, sowohl in Vakuolen als auch in Vakuolen-freiem Zytoplasma, in Form von kongophilen, gepaarten helikalen Aggregaten von Filamenten vor [Mirabella et al. 1996]. In dieser Arbeit wird zur Detektion von Neurofilament/Tau der Antikörper SMI-31 verwendet.

\subsubsection{Marker für Degeneration und Regeneration}

\subsubsection{Desmin}

Desmin ist ein Typ-3-Intermediärfilament und somit Teil des Zytoskeletts einer Muskelzelle [Lazarides und Hubbard 1976]. Die Expression dieses Markers wurde im Zusammenhang mit Muskelregeneration beschrieben und es konnte gezeigt werden, dass es als zusätzlicher Hinweis auf Zellstress in Muskelfasern dienen kann [Muth et al. 2009]. 


\subsubsection{Neuronal Cell Adhesion Molecule (NCAM)}

NCAM ist ein Adhäsions-Molekül, dessen Aufgabe unter anderem in Zell-ZellInteraktion besteht und das während der Myogenese exprimiert wird [Lyons et al. 1992]. Im reifen Muskel gilt es als Marker für Regeneration bei Zellschädigung [Winter und Bornemann 1999]. Im Rahmen der hIBM wurde kürzlich gezeigt, dass die Expression von NCAM durch die GNE-Mutation dahingehend beeinflusst wird, dass es eine erhöhte elektrophoretische Mobilität aufweist und somit einen möglichen diagnostischen Marker darstellt [Broccolini et al. 2010].

\subsubsection{Zellstress-assoziierte Marker}

\subsubsection{1 aB-Crystallin}

aB-Crystallin gehört zur Gruppe der Hitzeschockproteine und ist als Chaperon für die Proteinfaltung und Neufaltung fehlgefalteter Proteine zuständig. Bei stoffwechselbedingtem Zellstress wird es verstärkt exprimiert [Bennardini et al. 1992]. Es gilt sowohl in morphologisch auffälligen als auch in normal erscheinenden sIBMMuskelfasern als überexprimiert [Banwell und Engel 2000]. aB-Crystallin-positive, normal erscheinende sIBM-Muskelfasern wurden „X-Fasern“ benannt und scheinen eine zentrale Rolle in der frühen Phase der Muskelpathologie zu haben. Es konnte zudem gezeigt werden, dass bei der sIBM die mRNA-Expression von APP und aBCrystallin positiv korrelieren und dass pro-inflammtorischer Zellstress die Expression von aB-Crystallin und gleichzeitig von APP in Myotuben induziert [Muth et. al. 2009].

\subsubsection{Major Histocompatibility Complex I (MHC-I)}

Der Proteinkomplex MHC-I findet sich auf der Oberfläche nahezu aller kernhaltigen Zellen des Körpers und dient der Antigenpräsentation für die Immunerkennung, findet sich aber normalerweise nicht auf gesunden Muskelfasern. Es konnte gezeigt werden, dass fast alle nekrotischen Muskelfasern mit einer Invasion durch CD8 ${ }^{+}-$ Lymphozyten und auch nicht-nekrotische IBM-Muskelfasern MHC-I auf ihrer Zelloberfläche exprimieren [Emslie-Smith et al. 1989]. Bei inflammatorischen Myopathien, wie auch unter anderem bei der sIBM, gilt die Expression von MHC-I in 
der immunhistochemischen Färbung als Hinweis auf Antigen-vermittelte Zytotoxizität und als Hinweis auf Entzündung [Dalakas 1992]. In einer Studie aus dem Jahr 2008 konnte dann gezeigt werden, dass die Expression von MHC-I mit der von $\beta$-Amyloid und pro-inflammatorischen Markern MIG und IL-1 $\beta$ in sIBM-Muskelfasern kolokalisierte [Schmidt et al. 2008].

\subsubsection{Induzierbare Stickoxidsynthase (iNOS)}

iNOS ist ein Enzym, welches die Generierung von NO aus der Aminosäure L-Arginin bewirkt und somit an oxidativem Zellstress beteiligt ist und ebenfalls in Muskelzellen exprimiert wird [Williams et al.1994, Löffler et al. 2007]. Seine Expression wird unter anderem von pro-inflammatorischen Zytokinen und aber auch von $\beta$-Amyloid induziert [Baron et al. 2000], was die Überexpression von iNOS in sIBM-Muskelzellen erklären könnte [De Paepe et al. 2004]. Für die hIBM wurde ebenso eine nicht weiter quantifizierte Überexpression von iNOS beschrieben [Yang et al. 1998].

\subsubsection{Zytokine}

\subsubsection{Interleukin (IL) $1 \beta$, IL 6 und Interferon (IFN) Y}

Interleukine sind zu den Entzündungsmediatoren zählende Peptidhormone, die einen wesentlichen Bestandteil des Immunsystems darstellen. Sie leiten die spezifische Immunantwort ein. IL-1 $\beta$ gehört zur Untergruppe der Interleukin-1-Familie und wird u.a. von peripheren Monozyten im Blut auf einen Stimulus (z.B. Lipopolysaccharide) hin produziert [Löffler et al. 2007]. Es fördert daraufhin unter anderem die Bildung von verschiedenen Akut-Phase-Proteinen, IFN-y und IL-6 [Wingfield et al. 1986, Dinarello 1994 und 2005]. Zudem ist es in der Lage, NF-KB zu aktivieren und damit pro-inflammatorische Prozesse zu induzieren [Löffler et al. 2007]. In entzündlichen Myopathien wie der sIBM gilt es als hochreguliert [Lundberg et al. 1997] und es korreliert mit der Bildung von $\beta$-Amyloid in sIBM-Muskelfasern [Schmidt et al. 2008]. Auch IL-6 ist ein wichtiges pro-inflammatorisches Zytokin, dessen Freisetzung ebenfalls über Lipopolysaccharide oder die Bildung anderer Zytokine wie TNF- $\alpha$ und IL-1 $\beta$ getriggert wird [Löffler et al. 2007]. IL-6 stimuliert seinerseits ebenfalls die Bildung von Akut-Phase-Proteinen und gilt als eines der Schlüssel-Zytokine bei dem 
Übergang der unspezifischen in die spezifische Immunantwort [Jones 2005]. Gemeinsam mit IL-1 $\beta$ und TNF- $\alpha$ scheint es aber ebenso eine wichtige Rolle bei der Ausbildung chronischer Entzündungen und somit eine zusätzliche pathologische Rolle in Entzündungsprozessen zu haben [Reinecker et al. 1993, Chung 2005]. Bei der sIBM ist die mRNA-Expression von IL-6 gegenüber Kontrollen signifikant erhöht [Schmidt et al. 2008] und es konnte gezeigt werden, dass $\beta$-Amyloid die Expression von IL-6, nicht aber von IL-1 $\beta$ und TNF- $\alpha$ beeinflusst [Baron et al. 2001]. Das Glykoprotein IFN-y gehört zu den Typ-2-Interferonen und wird von T-Zellen und natürlichen Killerzellen auf bestimmte Stimuli (Zytokine wie TNF- $\alpha$, Viren und Bakterien) hin gebildet. Über verschiedene Mechanismen wirkt es hemmend auf die Virusvermehrung und bewirkt eine verstärkte Produktion von MHC-I und -II, sowie von MIG [Löffler et al. 2007]. Gemeinsam mit IL-1 und TNF beeinflusst es ebenso positiv die NO-Produktion in Muskelzellen und führt somit zu oxidativem Stress [Williams et al. 1994]. Bei entzündlichen Myopathien wird es zwar geringer exprimiert als andere Mediatoren, doch seine mRNA-Expression korrelierte positiv mit der von degenerativen Markern wie APP in sIBM-Muskelfasern und induzierte gemeinsam mit IL-1 $\beta$ die Expression von degenerativen Markern und anderen proinflammatorischen Zytokinen in Myotuben [Lundberg et al. 1997, Schmidt et al. 2008, Muth et al. 2009].

\subsubsection{Tumor-Nekrose-Faktor (TNF) $\alpha$ und transforming growth factor (TGF) $\beta$}

TNF- $\alpha$ gilt ebenso wie IL-1 $\beta$ und IL- 6 als pyogenes, sehr wirksames proinflammatorisches Zytokin und wird auf einen Endotoxin-Stimulus von Makrophagen und Monozyten freigesetzt. Es führt neben einer NF-kB-Aktivierung auch zur Apoptose. Zudem stimuliert es die Freisetzung und Bildung von Akut-PhaseProteinen und weiterer pro-inflammatorischer Zytokine und Chemokine wie IFN-y, IL6 und IL-1 $\beta$ [Löffler et al. 2007, Lundberg 2000]. Eine Überexpression im Muskel führt allerdings zur Atrophie und bei inflammatorischen Myopathien wird es überexprimiert, allerdings meist auf monozytische Zellen begrenzt [ $\mathrm{Li}$ et al. 2005, Lundberg 2000]. Im Gegensatz dazu wird TGF- $\beta$ konstant und stark überexprimiert bei entzündlichen Myopathien [Lundberg et al. 1997]. Es ist in zelluläre Prozesse wie Zell-Wachstum, Zell-Differenzierung, Apoptose und andere zelulläre Vorgänge involviert, gilt aber auch als einer der Hauptstimulatoren für die Bildung von 
Akutphase-Proteinen und hat damit auch Anteil an der Entstehung von Entzündungsreaktionen [Löffler et al. 2007].

\subsubsection{Monokine induced by gamma-Interferon (MIG)}

Monokine induced by gamma-Interferon (MIG) ist ein Chemokin, das im Rahmen von Entzündungsreaktionen von Makrophagen produziert wird und T-Lymphozyten rekrutiert [Farber 1990, Whiting et al. 2004]. Bei der sIBM ist es deutlich hochreguliert gegenüber Kontrollen und in immunhistochemischen Analysen zeigte es eine KoLokalisation zu APP und $\beta$-Amyloid [Raju et al. 2003, Schmidt et al. 2008].

\subsubsection{Makrophagen-Inflammatorisches Protein (MIP) $1 \alpha$ und $1 \beta$}

Die Chemokine MIP-1 $\alpha$ und $\beta$ werden ebenfalls von Makrophagen gebildet und können ihrerseits wiederum Granulozyten aktivieren und die Produktion einer Reihe von pro-inflammatorischen Zytokinen stimulieren [Irving et al. 1990, De Paepe et al. 2009]. Bei inflammatorischen Myopathien sind sie hochreguliert gegenüber nichtmyopathischen Kontrollen [Civatte et al. 2005]. Bei der sIBM ist die mRNAExpression von MIP-1 $\alpha$ und MIP-1 $\beta$ signifikant erhöht, sowohl gegenüber Kontrollen als auch anderen inflammatorischen Myopathien [Schmidt et al. 2008]. 


\section{Ziele der Arbeit}

Die Pathophysiologie der hIBM ist sehr komplex und noch unzureichend verstanden. Dies bedingt Probleme bei der Diagnostik und der Suche nach einer effektiven Behandlung der Erkrankung.

Übergeordnetes Ziel dieser Arbeit war es, die Expression von Markern für Proteinakkumulation, Degeneration und Regeneration, Entzündung und Zellstress im hIBM-Muskel zu analysieren und einen möglichen Zusammenhang zu untersuchen. Dieses könnte möglicherweise helfen, diagnostische und therapeutische Optionen abzuleiten und das weitere Verständnis der Pathophysiologie zu fördern.

Im Einzelnen sollten drei übergeordnete Fragestellungen bearbeitet werden:

1) Welche Rolle hat die Expression von Markern für Proteinakkumulation, Degeneration und Regeneration, Entzündung und Zellstress im hIBM-Muskel auf mRNA-Ebene?

Mittels quantitativer PCR sollte die Expression der Marker gemessen, mit der Expression nicht-myopathischer Kontrollpatienten verglichen und anschließend über Korrelationen mögliche Interaktionen der Marker untersucht werden.

2) Welche Rolle hat die Expression von Markern für Proteinakkumulation, Degeneration und Regeneration, Entzündung und Zellstress im hIBM-Muskel auf Proteinebene?

Über serielle immunhistochemische Färbungen und quantitative Analyse sollte die Expression, Ko-Lokalisation und Korrelation verschiedener Marker und ein möglicher Zusammenhang zu morphologischen Abnormalitäten im hIBM-Muskel untersucht werden. Besonderes Augenmerk wurde hierbei auf die Expression des Markers aBCrystallin in normal erscheinenden Muskelfasern gerichtet, da dieser als früher Marker eines Zellstresses bei der sIBM gilt.

3) Gibt es geschlechtsspezifische Unterschiede in der Expression der untersuchten Marker auf mRNA- und Proteinebene? 
Die hIBM-Patienten sollten in zwei Gruppen nach Geschlecht aufgeteilt werden und über statistische Methoden die Expression miteinander verglichen werden. Dies wäre die erste Untersuchung einer möglichen geschlechtsspezifischen Expression von krankheitsrelevanten Markern bei der hIBM. 


\section{Material und Methoden}

\subsection{Immunbiologische Materialien und Methoden}

\subsubsection{Patienten und Kontrollen}

Es wurden Muskelbiopsieproben von zehn Patienten mit hIBM vom National Center of Neurology and Psychiatry-National Institute of Neuroscience, Abteilung Neuromuskuläre Forschung, Kodaira, Tokyo, Japan, verwendet, zur Verfügung gestellt von Direktor Ichizo Nishino [siehe Tabelle 1].

Die Muskelbiopsate der Kontrollpatienten entstammen der Abteilung für Neuropathologie der Universitätsmedizin Göttingen und stellen Proben dar, in denen keine myopathischen Veränderungen diagnostiziert wurden [siehe Tabelle 2].

Die zur Verfügung gestellten Proben umfassten je 5 Objektträger mit Muskelbiopsieschnitten für histochemische Serienfärbungen und Gewebeproben zur RNA-Extraktion.

Tabelle 1: hIBM-Patienten mit Angaben zu Geschlecht und Alter

\begin{tabular}{ccc}
\hline hIBM-Patient & Geschlecht & Alter \\
\hline 1 & F & 37 \\
2 & M & 40 \\
3 & M & 42 \\
4 & F & 23 \\
5 & F & 33 \\
6 & M & 30 \\
7 & M & 23 \\
8 & F & 23 \\
9 & F & 49 \\
10 & F & 26 \\
\hline
\end{tabular}


Tabelle 2: Kontrollpatienten mit Angaben zu Geschlecht und Alter

\begin{tabular}{ccc}
\hline Kontrolle & Geschlecht & Alter \\
\hline 1 & M & 55 \\
2 & M & 41 \\
3 & F & 38 \\
4 & F & 52 \\
5 & F & 45 \\
6 & F & 73 \\
7 & M & 48 \\
8 & F & 49 \\
9 & F & 49 \\
\hline
\end{tabular}

\subsubsection{Hämalaun- und Eosin-Färbung}

Von den fünf Muskelbiospie-Objektträgern wurde je einer pro Patient mit Hämalaun und Eosin (H\&E) gefärbt. Für die H\&E-Färbung wurden die gefrorenen Muskelbiopsieschnitte mit 4\% PFA (Electron Microscopy Sciences, Hatfield, UK) 10 Min. fixiert, dreimal in PBS gewaschen und in Hämalaun (Roth, Karlsruhe, Deutschland) nach Mayer inkubiert (5-7 Min.). Danach wurden sie 10 Min. in $\mathrm{H}_{2} \mathrm{O}$ gewaschen und anschließend mit Eosin (Merck, Darmstadt, Deutschland) gefärbt (30 Sek.), daraufhin erneut mit $\mathrm{H}_{2} \mathrm{O}$ gewaschen. Zum Schluss wurden sie in aufsteigender Alkoholreihe in 70\%-, 96\%- und 99\%- Ethanol (je 5 Min.) und zweimal in Xylol (ROTH, Karlsruhe, Deutschland) inkubiert (10 Min.). Abschließend wurden die Muskelbiopsieschnitte mit Entellan (Merck, Darmstadt, Deutschland) eingedeckelt. 


\subsubsection{Immunhistochemische Färbungen}

Für die immunhistochemischen Serienfärbungen (indirekte Immunhistochemie) wurden die restlichen vier Objektträger pro Patient verwendet.

Zunächst wurden die Biospieschnitte mit einem Pap-Pen (SCI Science Services, München, Deutschland) umrandet.

Für die Primärantikörper zur Detektion von APP, MHC-I, $\alpha$ B-Crystallin, NCAM, IL-1 $\beta$ und $\beta$-Amyloid wurde eine Fixierung mit Aceton $\left(-20^{\circ} \mathrm{C} ; 10 \mathrm{Min}\right.$.), für die Primärantikörper iNOS und SMI-31 eine Fixierung mittels PFA-Methanol (4\% - PFA Electron Microscopy Sciences, Hatfield, UK) gewählt und bei Raumtemperatur für 10 Min. fixiert, danach dreimal mit PBS gewaschen. Die mit PFA-Methanol fixierten Objektträger wurden dann noch einmal in Methanol (bei $-20^{\circ} \mathrm{C}$ für $10 \mathrm{Min}$.) fixiert und danach ebenfalls wieder dreimal in PBS gewaschen.

Eine unspezifische Bindung wurde durch eine Blockierung (45 Min.) in 10\% bovinen Serumalbumin $(B S A)$ und 100\% Ziegenserum 1:1 (beides Jackson ImmunoResearch, West Grove, PA) verringert.

Die primären und sekundären Antikörper wurden mit einem Gemisch an 1\% BSA (Jackson ImmunoResearch, West Grove, PA) und 1xPBS im Verhältnis 1:10 verdünnt.

Danach wurden die Objektträger mit Inkubationsdauer und Inkubationstemperatur entsprechend der Tabelle 3 in einer feuchten, lichtgeschützten Kammer inkubiert. Anschließend wurden die Objektträger dreimal in PBS gewaschen und dann der entsprechende Sekundärantikörper aufgetragen (45 Min. Inkubationszeit). Die Verdünnung betrug jeweils 1:600 und es wurden Sekundärantikörper mit Spezifität gegen die jeweils verwendete Spezies des Primärantikörpers verwendet (Molecular probes, Invitrogen, Karlsruhe, Deutschland).

Diese Färbung wurde dann ein zweites Mal mit einem zweiten Primärantikörper und dem entsprechendem Sekundärantikörper wiederholt; es wurden doppelt gefärbt: APP und MHC-I, aB-Crystallin und NCAM, iNOS und SMI-31, IL-1 $\beta$ und 6E10. 
Abschließend erfolgte eine Kernfärbung mittels DAPI 1:50.000 (45 Sek.), danach wurden die Objektträger mit Fluoromount-G (Southern Biotech, Alabama, USA) eingedeckelt und im Dunkeln bei Raumtemperatur gelagert.

Tabelle 3: Primärantikörperliste: Liste für die bei den immunhistochemischen Färbungen verwendeten Antikörper nebst Inkubationszeit und Temperatur

\begin{tabular}{|c|c|c|c|}
\hline Spezifität & Hersteller & $\begin{array}{l}\text { Spezies und ggf. } \\
\text { Klon }\end{array}$ & $\begin{array}{l}\text { Inkubation und } \\
\text { Verdünnung }\end{array}$ \\
\hline $\begin{array}{l}\mathrm{\alpha B}- \\
\text { Crystallin }\end{array}$ & Serotec, Oxford, UK & $\begin{array}{l}\text { Kaninchen } \\
\text { polyklonal }\end{array}$ & 1h bei RT, $1: 1.000$ \\
\hline APP & Serotec, Oxford, UK & $\begin{array}{l}\text { Kaninchen } \\
\text { polyklonal }\end{array}$ & 1h bei RT, $1: 50$ \\
\hline$\beta$-Amyloid & Signet, Dedham, USA & Maus Klon 6E10 & $24 \mathrm{~h}$ bei $4^{\circ} \mathrm{C}, 1: 50$ \\
\hline MHC-I & Serotec, Oxford, UK & Ratte & 1h bei RT, 1:200 \\
\hline iNOS & $\begin{array}{l}\text { Chemicon/ Millipore, } \\
\text { Billerica,USA }\end{array}$ & $\begin{array}{l}\text { Kaninchen } \\
\text { polyklonal }\end{array}$ & 1h bei RT, $1: 500$ \\
\hline IL-1 $\beta$ & $\begin{array}{l}\text { Abcam, Cambridge, } \\
\text { USA }\end{array}$ & $\begin{array}{l}\text { Kaninchen } \\
\text { polyklonal }\end{array}$ & $24 \mathrm{~h}$ bei $4^{\circ} \mathrm{C}, 1: 100$ \\
\hline NCAM & $\begin{array}{l}\text { Neomarkers Labvision, } \\
\text { Fremont, USA }\end{array}$ & Maus Klon Eric-1 & 1h bei RT, 1:100 \\
\hline SMI-31 & $\begin{array}{l}\text { Abcam, Cambridge, } \\
\text { USA }\end{array}$ & Maus monoklonal & 1h bei RT, $1: 2.000$ \\
\hline
\end{tabular}

\subsubsection{Fluoreszenz-mikroskopische Analyse}

Die quantitative Analyse und Auswertung der immunhistochemischen Färbungen wurden am Fluoreszenzmikroskop Axiovert 200M mittels eines 20er Objektivs durchgeführt. Die Filtereinstellungen entsprachen hierbei der Emissionswellenlänge des verwendeten Farbstoffs (rot für Alexa 594, grün für Alexa 488, blau für DAPI) und die Belichtungseinstellung wurde für jeden Patienten jeweils gleich gehalten. Die Aufnahmen wurden dann mit einer CCD-Kamera (Retiga 1.300, Qimaging, Burnaby, BC, Canada) angefertigt. Pro Patient wurden dann jeweils vier Aufnahmen pro Färbung angefertigt und die korrespondierenden Bereiche bei jedem Patienten analysiert. 


\subsection{Molekularbiologische Methoden und Materialien}

\subsubsection{RNA-Extraktion aus Gewebe}

Das gefrorene Gewebe der Muskelbiospsieschnitte wurde in einem 1,5 ml Gefäß mit $500 \mu \mathrm{l}$ Trizol aufgefüllt und mittels eines Zellmörsers homogenisiert. Nach Inkubation (5 Min. bei Raumtemperatur) wurden die Eppendorf-Gefäße bei $4^{\circ} \mathrm{C}$ für $10 \mathrm{Min}$. mit 14.000 U/Min. zentrifugiert und der Überstand in ein neues Gefäß überführt. $5 \mu \mathrm{g}$ „linear Acrylamid“ (Ambion 9.520) wurden dazugegeben und die Eppendorf-Gefäße für 10 Sek. gemischt. Danach wurden $100 \mu$ Chloroform hinzugegeben, erneut für 30 Sek. gemischt und erneut für $5 \mathrm{Min}$. bei $4^{\circ} \mathrm{C}$ mit $14.000 \mathrm{U} / \mathrm{Min}$. zentrifugiert. Der Überstand wurde ebenfalls wieder in ein neues Eppendorf-Gefäß überführt und $240 \mu \mathrm{l}$ Isopropanol hinzugegeben. Danach wurden die Gefäße geschüttelt und gemischt. Die Präzipitation geschah für $30 \mathrm{Min}$. bei $-80^{\circ} \mathrm{C}$, im Anschluss erfolgte erneut eine Zentrifugation der Gefäße für $30 \mathrm{Min}$. bei $4^{\circ} \mathrm{C}$ mit $14.000 \mathrm{U} / \mathrm{Min}$. Der Überstand wurde verworfen. Das Pellet wurde mit $500 \mu \mathrm{l}$ RNAse-freiem 70\%Ethanol gewaschen und wiederum für $10 \mathrm{Min}$. bei $4^{\circ} \mathrm{C}$ mit $14.000 \mathrm{U} /$ Min. zentrifugiert. Nun wurde der Überstand vorsichtig abgenommen, wieder verworfen und der Rest für 1 Min. abzentrifugiert. Nachdem das Pellet für ein bis zwei Min. an der Luft getrocknet worden war, wurde die isolierte RNA in $33 \mu$ RNAse-freiem $\mathrm{H}_{2} \mathrm{O}$ gelöst, die Konzentration bestimmt und bis zum Gebrauch bei $-80^{\circ} \mathrm{C}$ gelagert. Zur Bestimmung der Konzentration und der Reinheit wurde das NanoDropSpektrophometer (PEQLAB, Erlangen, Deutschland) entsprechend den Herstellerangaben benutzt. Die gesamte Reaktion wurde auf Eis durchgeführt.

\subsection{2 cDNA-Synthese}

Die Umschreibung der messengerRNA (mRNA) zur (complementary) cDNA erfolgte mit SuperScript-Kit (Invitrogen, Karlsruhe, Deutschland). Die Verwendung erfolgte entsprechend der Herstellerangaben. Als Primer für die DNA-Polymerase wurde ein Oligo-Desoxythymidin-Nukleotid komplementär zur mRNA verwendet und durch Desoxyribonukleotidtriphosphat-Mix (Invitrogen, Karlsruhe, Deutschland) und reverse Transkriptase (Invitrogen, Karlsruhe, Deutschland) wurde der cDNA-Strang gebildet. 
Die anschließende Reaktion eliminierte die Ursprungs-RNA und bildete den cDNADoppelstrang. Die cDNA wurde bei $-20^{\circ} \mathrm{C}$ gelagert.

\subsubsection{Quantitative (real-time) Polymerase-Kettenreaktion}

Die RT-PCR erforderte die Verwendung des TaqMan-Proben-Systems von Applied Biosystems (Applied Biosystems, Foster City, USA) und wurde an einem 7.500 RealTime-PCR-System (Applied Biosystems, Foster City, USA) durchgeführt. Die verwendeten Primer wurden von Applied Biosystems (Foster City, USA) bezogen [siehe Tabelle 4].

Tabelle 4: Primer-Proben der RT-PCR

\begin{tabular}{|c|c|}
\hline Genname/ Molekül & Assay ID \\
\hline amyloid precursor protein (APP) & HS00169098_m1 \\
\hline aB-Crystallin & HS00157107_m1 \\
\hline Desmin & HS00157258_m1 \\
\hline Glycerinaldehyd-3-Phosphat-Dehydrogenase (GAPDH) & HS99999905_m1 \\
\hline Induzierbare Stickstoffsynthase (iNOS) & HS00167223_m1 \\
\hline Interferon y (IFN-y) & HS00174143_m1 \\
\hline Interleukin $1 \beta(\mathrm{IL}-1 \beta)$ & HS00174097_m1 \\
\hline Interleukin 6 (IL-6) & HS00174131_m1 \\
\hline monokine induced by gamma interferon (MIG) & HS00171063_m1 \\
\hline Makrophagen-Inflammatorisches Protein $1 \alpha($ MIP-1 $\alpha)$ & HS00234142_m1 \\
\hline Makrophagen-Inflammatorisches Protein $1 \beta$ (MIP-1 $\beta$ ) & HS00605740_g1 \\
\hline major histocompatibility complex I (MHC-I) & 6FAMTGGAGAACGGGAAGGA \\
\hline neuronal cell adhesion molecule (NCAM) & HS00169851_m1 \\
\hline Tumor-Nekrose Faktor $\alpha($ TNF- $\alpha)$ & HS00174128_m1 \\
\hline transforming growth factor (TGF- $\beta$ ) & HS00171257_m1 \\
\hline Ubiquitin & HS00430290_m1 \\
\hline
\end{tabular}


Für die Quantifizierung der mRNA-Expression der einzelnen Marker wurden für je $20 \mu \mathrm{l}$ Ansatz $10 \mu \mathrm{l} \mathrm{PCR}$ 2xMix (Invitrogen, Karlsruhe, Deutschland), 8,5 $\mu \mathrm{l} \mathrm{H}_{2} \mathrm{O}$, $0,04 \mu \mathrm{l}$ ROX (Invitrogen, Karlsruhe, Deutschland), 0,5 $\mu \mathrm{l} \mathrm{cDNA}$ und $1 \mu \mathrm{l}$ Primer Probe verwendet. Der PCR 2xMix beinhaltet die Taq-DNA-Polymerase, Magnesiumchlorid, DNA-Glykosylasen, Desoxyribonukleosidtriphosphat und Stabilisierer. Der Farbstoff ROX (Carboxy-X-Rhodamin) wurde zum Ausgleich eventueller pipettierbedingter Volumenunterschiede der Proben hinzugegeben. Gemessen wurde die mRNAExpression im Vergleich zur mRNA-Expression von GAPDH als Vergleichswert. Der Ablauf der Polymerasekettenreaktion ist in Tabelle 5 aufgeführt.

Die mRNA-Expression wurde jeweils in Triplikaten bestimmt.

Tabelle 5: RT-PCR-Programm

$\left.\begin{array}{llll}\hline \text { Schritt } & \text { Dauer } & \text { Temperatur } & \text { Zyklenzahl } \\ \hline \text { Initialisierung } & 2 \mathrm{Min} . & 50^{\circ} \mathrm{C} & \\ \text { Hitzeaktivierung } & 10 \mathrm{Min} . & 95^{\circ} \mathrm{C} \\ \text { Denaturierung } & 15 \mathrm{Sek} . & 95^{\circ} \mathrm{C} \\ \text { Hybridisierung/Elongation } & 1 \mathrm{Min} . & 60^{\circ} \mathrm{C}\end{array}\right]$

\subsection{Statistische Methoden}

Die statistischen Analysen wurden alle mit Graph Pad Prism V4 (San Diego, USA) durchgeführt. Unterschiede zwischen hIBM-Patienten und Kontroll-Patienten wurden mittels T-Test berechnet und zusätzlich bei nicht Gauss'scher Normalverteilung mittels Mann-Whitney-U-Test. Die Gauss'sche Normalverteilung wurde mittels Graph Pad Prism V4 (San Diego, USA) ermittelt. Signifikanzen wurden wie folgt definiert: ${ }^{*} \mathrm{P}=\leq 0,05,{ }^{* *} \mathrm{P}=\leq 0,01,{ }^{* * *} \mathrm{P}=\leq 0,001$. Eine Berechnung statistischer Ausreißer wurde mit Hilfe des Grubb's Test von Graph Pad (San Diego, USA) durchgeführt. 


\section{Ergebnisse}

\subsection{Einleitung}

Obwohl die Mutation im GNE-Gen bereits seit längerer Zeit beschrieben ist [Eisenberg et al. 2001], sind die genauen Pathomechanismen um die Entstehung der typischen Muskelpathologie nicht verstanden. Wie die Mutation im GNE-Gen mit daraus entstehender Hyposialylierung der Skelettmuskulatur [Nishino et al. 2005] die Entwicklung von Vakuolen und anderen strukturellen Abnormalitäten in hIBMMuskelzellen beeinflusst, ist bisher unklar. Eine deutliche entzündliche Komponente, wie sie für die sIBM beschrieben worden ist [Lotz et al. 1989], wurde bei der hIBM bislang nicht gesehen [Askanas und Engel 1998]. Ziel dieser Arbeit soll nun sein, neben Markern für Proteinakkumulation auch pro-inflammatorische Marker und Marker für Zellstress im Skelettmuskel der hIBM auf mRNA- und Proteinebene zu untersuchen. Um ein genaueres Bild von den Vorgängen in der Muskelzelle der hIBM zu erhalten, haben wir die mRNA-Expression der relevanten Marker bei zehn hIBMPatienten analysiert und mit denen von neun Kontrollpatienten verglichen.

\section{2 mRNA-Expression von Markern für Entzündung, Zellstress und Proteinakkumulation bei der hIBM}

Im Muskel von zehn hIBM-Patienten wurde mittels RT-PCR die mRNA-Expression von verschiedenen Markern bestimmt. Es wurden als Marker für Proteinakkumulation die Expression von APP und Ubiquitin, als Marker für Degeneration und Regeneration die Expression von Desmin und NCAM analysiert. Die Expression zellstress-assoziierter Marker wie aB-Crystallin, MHC-I und iNOS und die der proinflammatorischen Zytokinen wie IFN- $\gamma$, IL-1 $\beta$, IL-6, TNF- $\alpha$ und TGF- $\beta$ wurden ebenso gemessen wie die Expression der Chemokine MIG, MIP-1 $\alpha$ und MIP-1 $\beta$. 


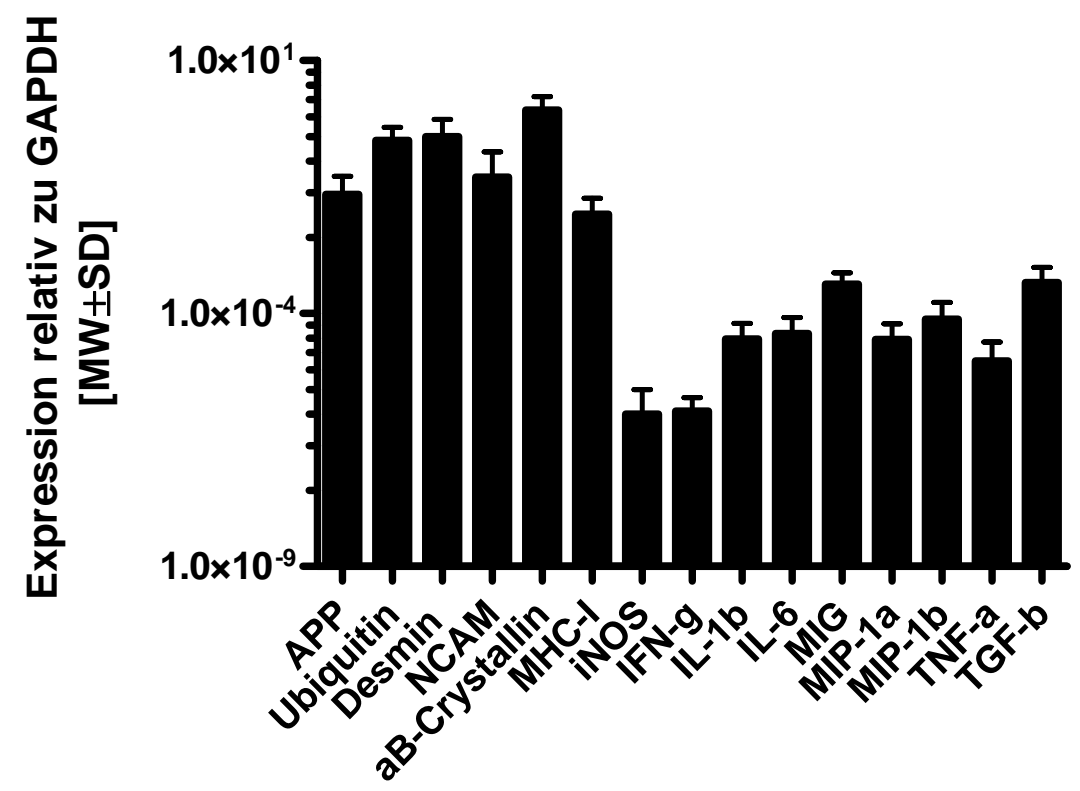

Abbildung 2: mRNA-Expression im Muskel bei hIBM; alle Marker sind detektierbar in den Muskelproben von zehn Patienten mit hIBM; Marker für Proteinakkumulation, Regeneration und Zellstress sind am höchsten exprimiert. Die pro-inflammatorischen Zytokine und iNOS bleiben geringer exprimiert. Die Daten zeigen Mittelwert und Standardabweichung.

Die Expression wurde jeweils relativ zur Expression des Enzyms Glycerinaldehyd-3Phosphat-Dehydrogenase (GAPDH) gemessen, was ubiquitär in allen Zellen des Körpers vorkommt. Für alle Marker wurde eine Berechnung statistischer Ausreißer mittels des Grubb's Test durchgeführt. Die Marker IL-1 $\beta$, IL-6 und TGF- $\beta$ wurden lediglich bei sieben der zehn hIBM-Patienten untersucht, da von manchen Patienten unzureichend RNA vorhanden war. Insgesamt waren alle gemessenen Marker in den hIBM-Proben detektierbar. Die Expression der Marker Ubiquitin, Desmin, NCAM und $\alpha B-C r y s t a l l i n$ war am höchsten, die der pro-inflammatorischen Marker IFN- $\gamma$, TNF- $\alpha$ und iNOS am niedrigsten [siehe Abbildung 2]. UBB war lediglich bei neun von zehn, Desmin bei sechs von zehn, iNOS bei drei von zehn, IFN-y bei sieben von zehn, IL$1 \beta$ bei fünf von sieben, IL- 6 bei sechs von sieben, MIP-1a bei neun von zehn und TNF- $\alpha$ bei sieben von zehn Patienten detektierbar. Die mRNA-Expression eines Patienten war bei sieben Parametern ein statistisch belegter Ausreißer (Patient 1 aus Tabelle 1). 


\section{3 mRNA-Expression von Markern für Entzündung, Zellstress und Proteinakkumulation im Vergleich zu Kontrollen}

Die mRNA-Expression sämtlicher untersuchter Marker relativ zur Expression von GAPDH wurde mit der mRNA-Expression von nicht myopathischen Kontrollen ebenfalls relativ zur Expression von GAPDH verglichen. Zuvor wurde eine statistische Ausreißer-Berechnung durchgeführt und die Werte ohne Ausreißer für die weiteren statistischen Berechnungen genutzt. APP, $\alpha \mathrm{B}-\mathrm{Crystallin}$, Desmin, IFN- $\mathrm{\gamma}$,

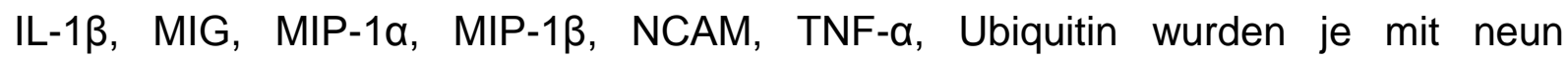
Kontrollpatienten-Proben, IL-6 und TGF- $\beta$ mit sechs und iNOS und MHC-I mit je drei Kontrollpatienten verglichen, da keine ausreichende RNA der jeweiligen Patienten mehr verfügbar war. Bei sämtlichen untersuchten Markern zeigten sich in der mRNAExpression keine statistisch signifikanten Unterschiede zu den Kontrollpatienten. Die mRNA-Expressionen von APP, NCAM, MHC-I, TNF- $\alpha$ und TGF- $\beta$ war aber bei der hIBM tendenziell erhöht im Vergleich zu den Kontrollen. IL-1 $\beta$ und IL-6 waren hingegen tendenziell höher in den Kontrollen exprimiert [siehe Abbildung 3]. Da iNOS nur an einem Kontrollpatienten detektierbar war, wurde hier keine statistische Ausreißerberechnung vorgenommen. 


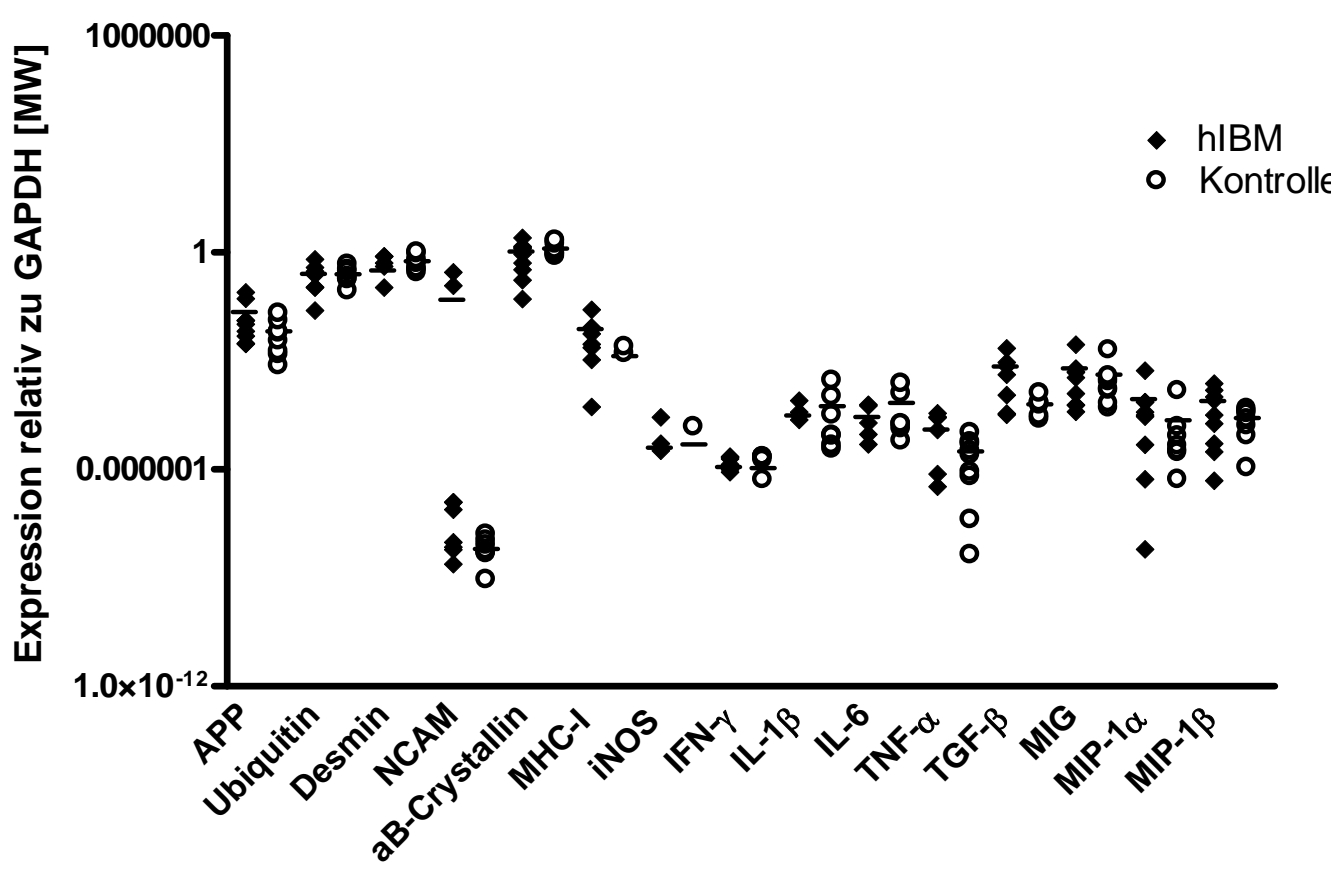

Abbildung 3: mRNA-Expression von Patienten mit hIBM im Vergleich zu nichtmyopathischen Kontrollen; APP, NCAM, MHC-I, TNF- $\alpha$ und TGF- $\beta$ sind in den Muskelbiopsien von hIBM-Patienten tendenziell höher exprimiert als in den Kontrollen, ohne jedoch statistische Signifikanz zu erreichen. Durch die Achsenskalierung wurde ein Wert

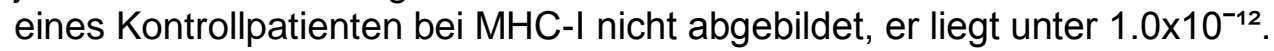

\subsection{Korrelation der mRNA-Expression bei hIBM von Markern für Proteinakkumulation und Zellstress mit pro-inflammatorischen Mediatoren}

Für sämtliche untersuchten Marker wurden Korrelationen der mRNA-Expression berechnet. Dadurch sollten Ko-Expressionen der Marker analysiert und Beziehungen der Marker zueinander aufgestellt werden. Nach Ausschluss der statistischen Ausreißer mittels Grubb's Test korrelierte APP mit dem Marker für Proteinakkumulation UBB $\left({ }^{*} P<0,05\right)$, und den pro-inflammtorischen Zytokinen MIP1a $\left({ }^{* * *} \mathrm{P}<0,001\right)$, MIP-1 $\beta\left({ }^{*} \mathrm{P}<0,05\right)$ und MHC-I $\left({ }^{* * *} \mathrm{P}<0,001\right)$. Die mRNA-Expression des Hitzeschockproteins $\alpha B$-Crystallin korrelierte positiv mit dem Degenerations- und Regenerationsmarker Desmin $\left({ }^{* * *} P<0,001\right)$, sowie den pro-inflammtorischen Zytokinen IL-6 ( $\left.{ }^{*} \mathrm{P}<0,05\right)$ und MIP-1 $\beta\left({ }^{*} \mathrm{P}<0,05\right)$. TGF- $\beta$ als Marker für Entzündung korrelierte ebenfalls positiv mit den pro-inflammatorischen Markern MIP-1 $\alpha$ $\left({ }^{* * *} \mathrm{P}<0,001\right), \mathrm{MIP}-1 \beta\left({ }^{* * *} \mathrm{P}<0,001\right)$ und TNF- $\alpha\left({ }^{*} \mathrm{P}<0,05\right)$ [siehe Abbildung 4]. 
A
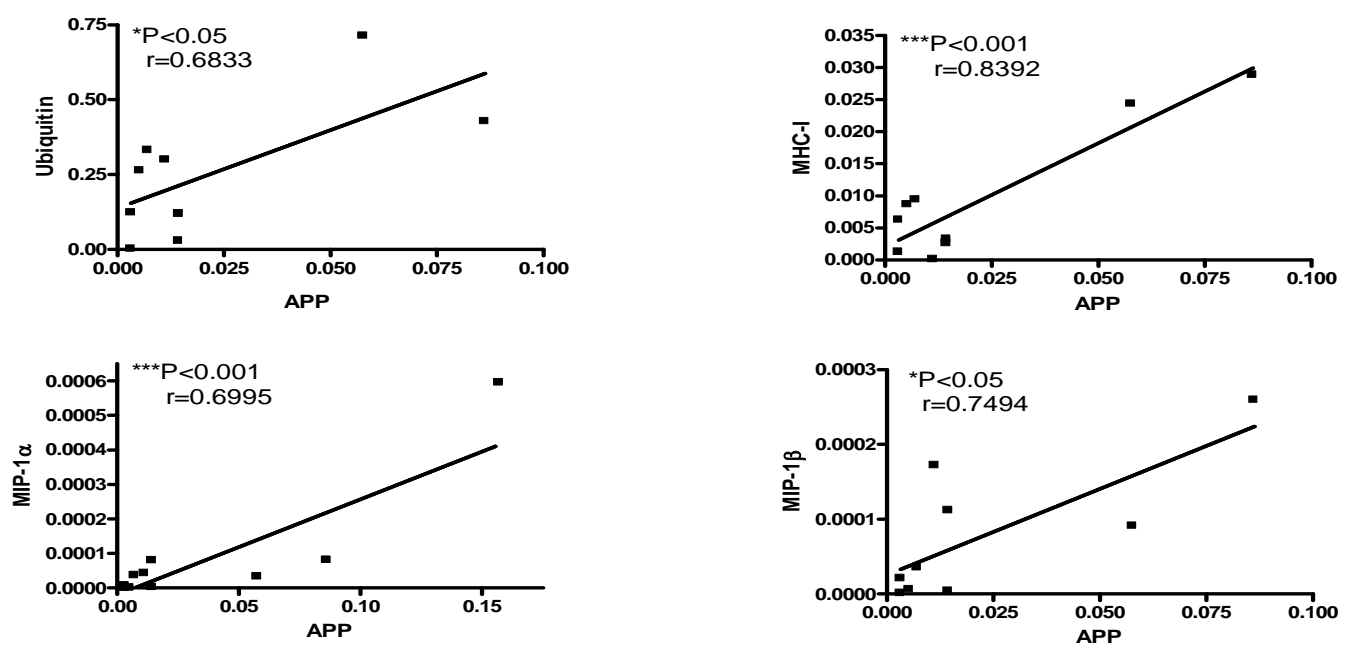

B
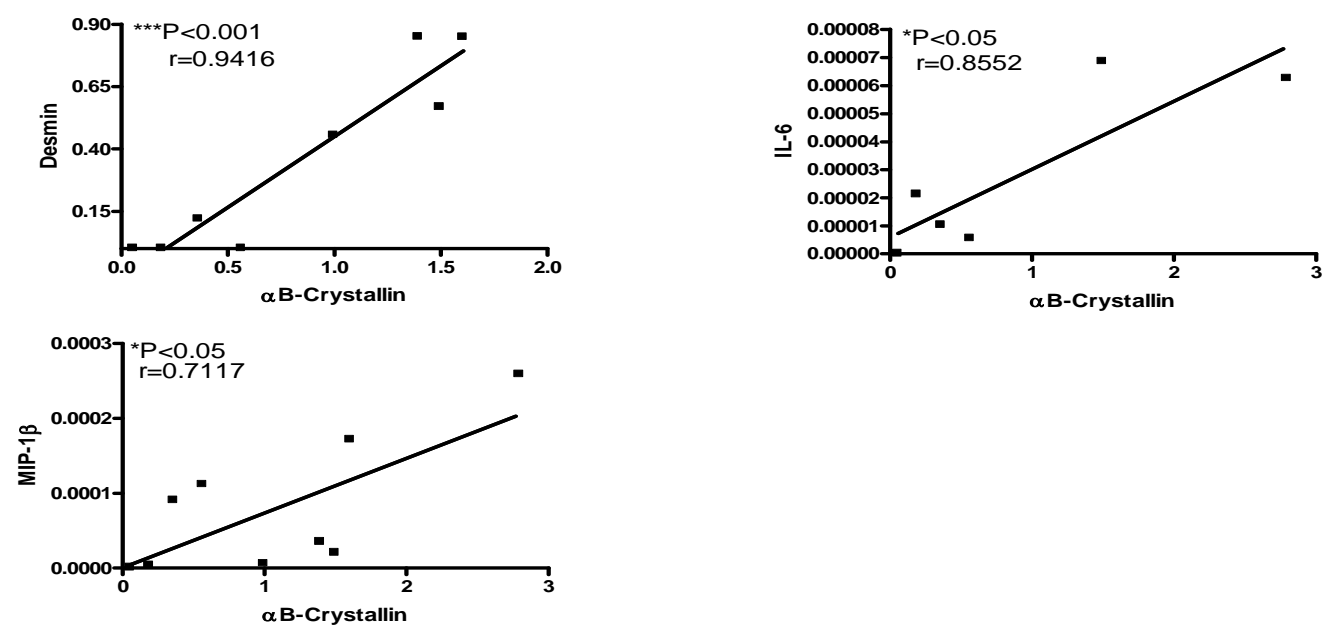

C
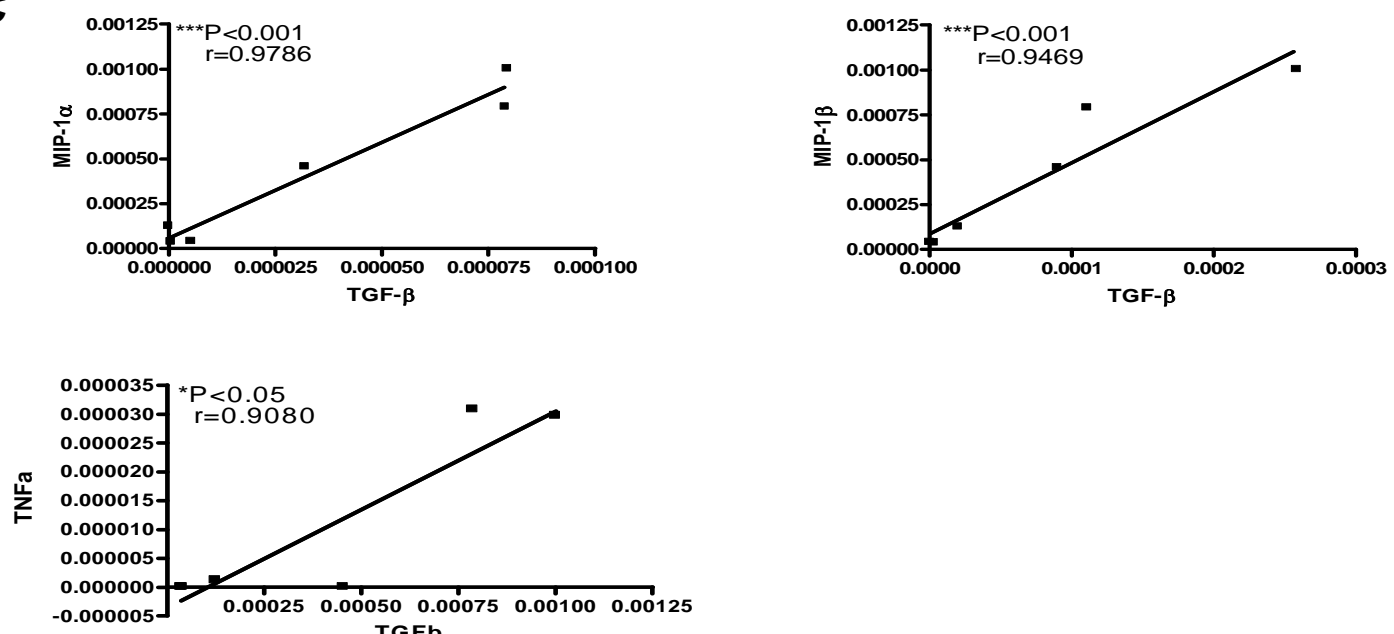
TGFb

Abbildung 4: Korrelation der mRNA-Expression der Marker APP, aB-Crystallin und TGF- $\beta$; A) Die Expression von APP korreliert signifikant mit der von Ubiquitin und proinflammatorischen Mediatoren wie MHC-I, TNF- $\alpha$, TGF- $\beta$, MIP-1 $\alpha$ und MIP-1 $\beta$; B) Die Expression von $\alpha B$-Crystallin korreliert signifikant mit der von Desmin, IL-6, und MIP-1 $\alpha$; $\mathbf{C}$ ) Die Expression von TGF- $\beta$ korreliert signifikant mit der von TNF- $\alpha$, MIP- $1 \alpha$ und MIP-1 $\beta$. 


\subsection{Quantitative Analyse seriell gefärbter Schnitte von Patienten mit hIBM:} Marker für Proteinakkumulation, Zellstress und Entzündung

Die Muskelbiopsie-Schnitte von zehn hIBM-Patienten wurden in Serie gefärbt und mittels immunhistochemischer Färbungen bezüglich der Protein-Expression von $\beta$ Amyloid (durch die Färbung mit dem spezifischen monoklonalen Antikörper 6E10), seines Vorläuferproteins APP, des Antikörpers für Neurofilamente/phosphoryliertes Tau (SMI-31) und des Degenerations- und Regenerationsmarkers NCAM untersucht. Ebenso wurde die Expression der pro-inflammatorischen Marker IL-1 $\beta$ und MHC-I und iNOS als Marker für Zellstress analysiert. Die Expression des Hitzeschockproteins aB-Crystallin wurde als Marker für Degeneration und Zellstress bestimmt [siehe Abbildung 5]. Dabei wurden insgesamt 2.871 Muskelfasern aus den jeweils korrespondierenden Arealen in Muskelbiopsieschnitten untersucht, pro Patient zwischen 107 und 498 Muskelfasern, und mittels einer CCD-Kamera mit einem 20er Objektiv fotografiert. Die Aufnahmen wurden dann bezüglich der Expression immunhistochemischer Marker und morphologischer Auffälligkeiten untersucht. Die angegebenen Prozentzahlen entsprechen dem Prozentwert der für die einzelnen Marker auswertbaren Fasern. Die quantitative Auswertung der Muskelfasern ergab daraufhin eine Überexpression der Proteine für iNOS $(16,3 \pm 10,2 \%$ jeweils $M W \pm S D)$ und aB-Crystallin $(10,2 \pm 2,0 \%)$, sowie eine mäßige Expression des Degenerations- und Regenerationsmarkers $\operatorname{NCAM}(4,8 \pm 2,4)$ und des

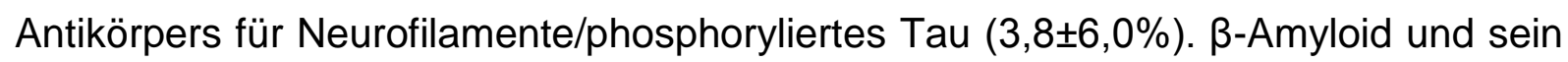
Vorläufermolekül APP waren hingegen nur sehr schwach und in lediglich 2,0 $\pm 2,0 \%$ ( $\beta$-Amyloid) und 1,8 $\pm 1,7 \%$ (APP) der Fasern als positiv zu erkennen. Ebenso zeigten

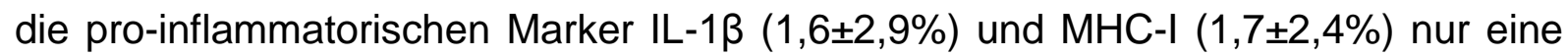
sehr geringe Expression in den hIBM-Muskelfasern [siehe Abbildung 4]. Eine weitere Subtypen-Analyse der Fasern, die als positiv für aB-Crystallin und iNOS gewertet wurden ergab, dass über ein Drittel der aB-Crystallin-positiven Fasern ebenso eine Überexpression für NCAM zeigte $(31,0 \pm 31,4 \% \mathrm{MW} \pm \mathrm{SD})$ und über ein Fünftel eine

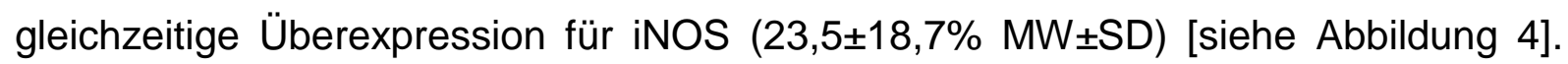
Auch iNOS-positive Fasern zeigten sich in über $15 \%$ als doppelt positiv für $\alpha \mathrm{B}-$ 

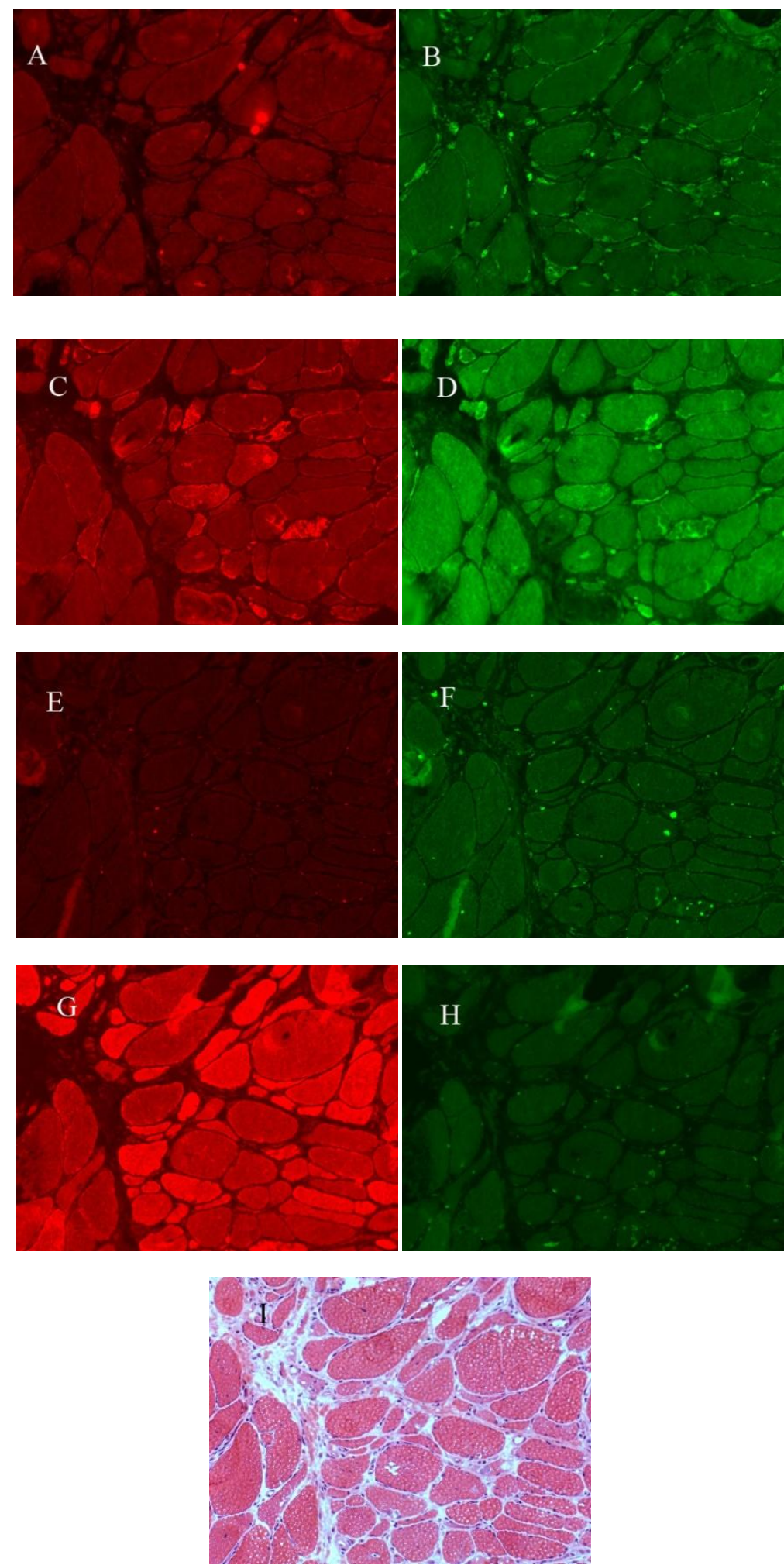

Abbildung 5: Immunohistochemische Doppel-Färbung in Serie an Muskelbiopsieproben von Patienten mit hIBM; Doppelfärbung von A) APP und B) MHC-I zeigt ein nachweisbare Expression der Marker, Doppelfärbung von C) $\alpha B$-Crystallin und D) NCAM zeigt eine erhöhte Expression für $\alpha B$-Crystallin, Doppelfärbung von $E$ ) IL-1 $\beta$ und $F$ ) $\beta$ Amyloid zeigt eine geringe Expression der Marker, Doppelfärbung von $\mathbf{G}$ ) iNOS und $\mathbf{H}$ ) Neurofilament/Tau zeigt eine erhöhte Expression für iNOS, I) H\&E- Färbung (jeweils mit 20er Objektiv aufgenommen). 
Crystallin $(16,1 \pm 8,9 \% \mathrm{MW} \pm \mathrm{SD})$ und in über $10 \%$ doppelt positiv für $\operatorname{NCAM}(10,7 \pm$ $12,2 \% \mathrm{MW} \pm \mathrm{SD}$ ) [siehe Abbildung 6].

Die anderen untersuchten Marker zeigten weitaus geringere Ko-Lokalisationen zu aB-Crystallin und iNOS [siehe Abbildung 6].

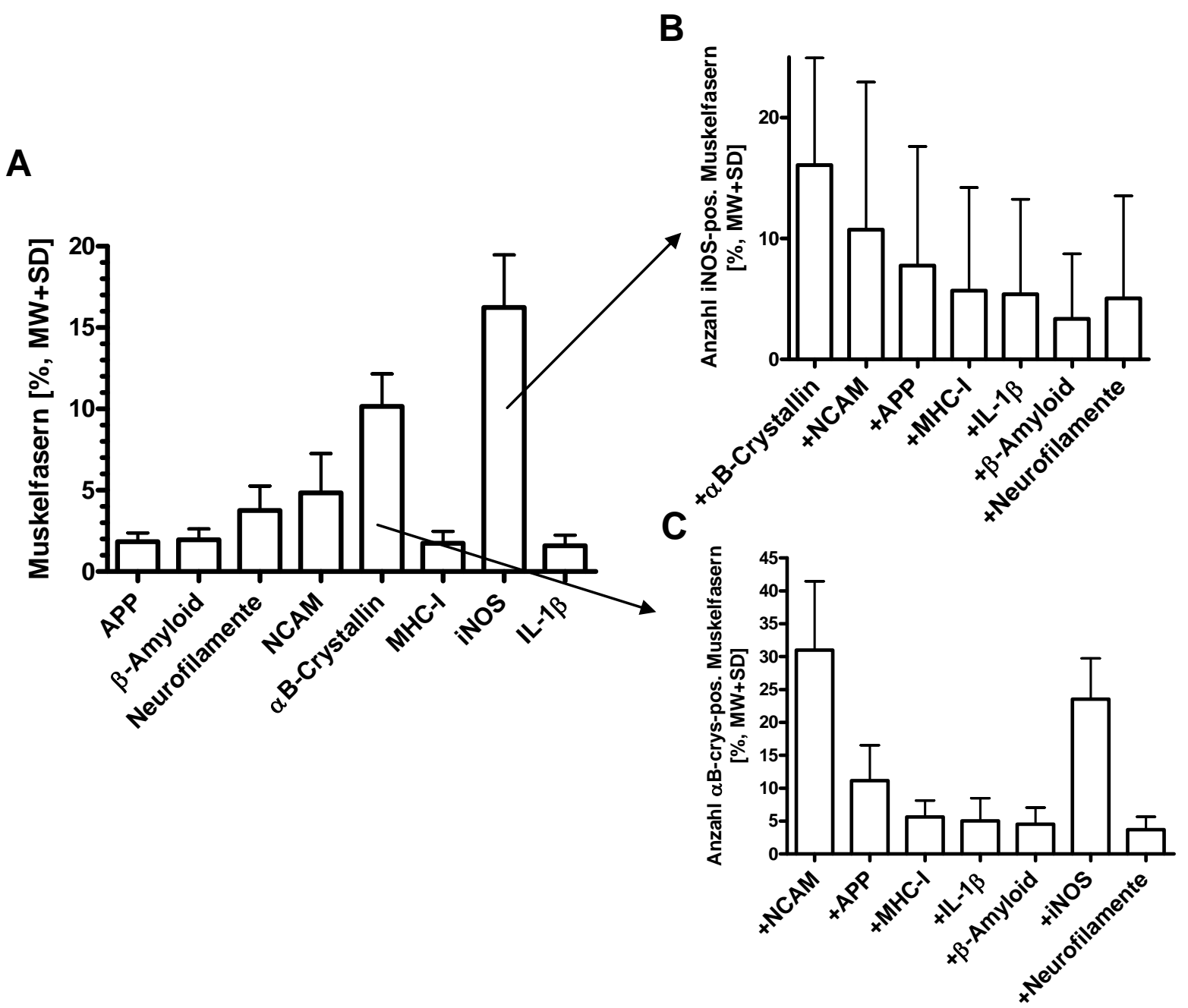

Abbildung 6: Immunhistochemische Färbungen der hlBM-Muskelbiopsie-Proben; A) die quantitative Analyse der Proteinexpression in hIBM-Muskelfasern ergibt, dass vor allem aB-Crystallin und iNOS überexprimiert werden, B) bei der Subtypen-Analyse iNOS-positiver hIBM-Muskelfasern, finden sich für aB-Crystallin und NCAM hohe Werte der KoLokalisationen C) bei der Subtypen-Analyse von aB-Crystallin-positiven hIBM-Muskelfasern, finden sich für iNOS und NCAM hohe Werte der Ko-Lokalisationen. 


\subsection{Korrelation der Proteinexpression von degenerativen, pro- inflammatorischen und Zellstress-assoziierten Markern}

Um Zusammenhänge der relevanten Marker auch auf Proteinebene zu untersuchen, wurden statistische Korrelationen eben dieser berechnet. Hierbei zeigte sich eine positive Korrelation der Proteinexpression des Hitzeschockproteins aB-Crystallin mit der des Degenerations- und Regenerationsmarkers NCAM, des proinflammatorischen Markers MHC-I und des Zellstress-assoziierten Markers iNOS. Ebenso korrelierten einerseits NCAM mit MHC-I und andererseits iNOS mit MHC-I, sowie iNOS und NCAM untereinander [siehe Abbildung 7].
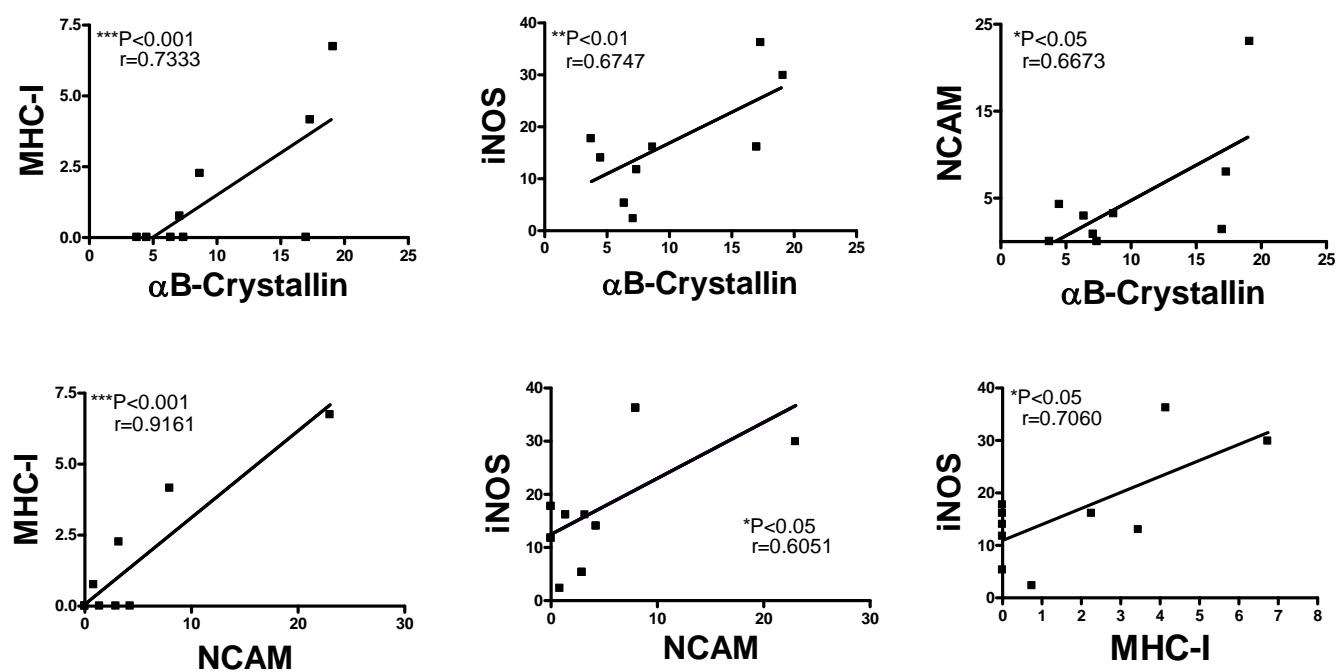

Abbildung 7: Interaktion der Proteinexpression von Markern für Proteinakkumulation, Entzündung und Zellstress; aB-Crystallin, NCAM, iNOS und MHC-I korrelieren signifikant miteinander. 


\subsection{Quantitative, lichtmikroskopische Analyse der H\&E-Färbung}

Als morphologisches Korrelat der Pathologie des Muskels der hIBM gelten neben den vakuolären Einschlüssen auch atrophe Fasern [Askanas et al. 1993]. In dieser Arbeit wurden mittels der H\&E-Färbung die Muskelbiospieproben der hIBM-Patienten auf morphologischen Auffälligkeiten wie Atrophie, Hypertrophie und vakuoläre Einschlüsse untersucht. Fasern mit internalisierten Nuklei und geteilte Fasern wurden ebenfalls als unspezifisch zu den morphologisch auffälligen Fasern gezählt. In der quantitativen, lichtmikroskopischen Auswertung der Färbungen zeigten sich

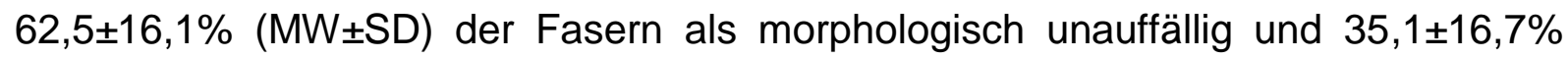
$(\mathrm{MW} \pm \mathrm{SD})$ als morphologisch auffällig, wovon sich der Großteil als atrophe Fasern (18.3 $\pm 10,5 \% \mathrm{MW} \pm \mathrm{SD})$, gefolgt von hypertrophen Fasern $(10,6 \pm 8,9 \% \mathrm{MW} \pm \mathrm{SD})$ und Fasern mit vakuolären Einschlüssen $(2,7 \pm 4,4 \% \mathrm{MW} \pm \mathrm{SD})$ darstellte [siehe Abbildung 8]. Die restlichen Fasern waren entweder nicht auswertbar (Differenz von 100\%morphologisch unauffällige und auffällige Fasern) oder zeigten oben genannte unspezifische morphologische Auffälligkeiten (Differenz von 35,1\% - atrophe Fasern, hypertrophe Fasern und Fasern mit vakuolären Einschlüssen). 


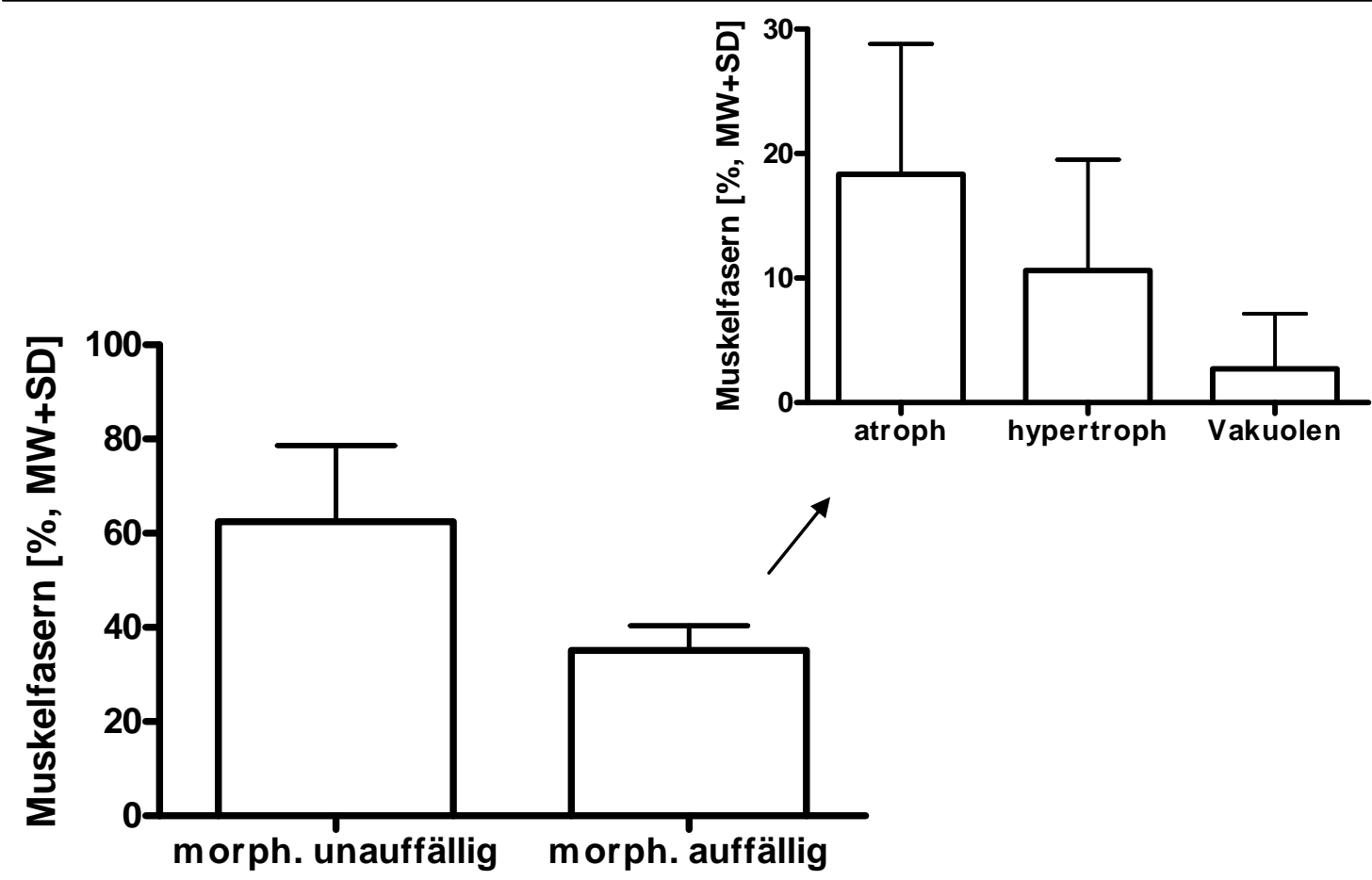

Abbildung 8: Quantitative Analyse morphologischer Strukturen in hIBM-Muskelfasern; zahlenmäßig überwiegen Muskelfasern ohne strukturelle Abnormalitäten (morph-), der überwiegende Teil der morphologisch auffälligen Fasern (morph+) ist atroph, gefolgt von hypertrophen Fasern und Fasern mit vakuolären Einschlüssen.

Ebenso wurde die Expression der untersuchten Marker in der immunhistochemischen Analyse und das morphologische Erscheinungsbild der hIBM-Muskelfasern verglichen. Dabei zeigte sich, dass sowohl in atrophen als auch in vakuolisierten Fasern die Expression des Hitzeschockproteins aB-Crystallin jeweils am höchsten war $(24,4 \pm 14,6 \%$ in atrophen, $20,2 \pm 26,3 \%$ in vakuolisierten Fasern $(\mathrm{MW} \pm \mathrm{SD}))$, gefolgt von iNOS $(21,5 \pm 22,3 \%$ in atrophen, $11,8 \pm 26,4 \%$ in vakuolisierten Fasern $(\mathrm{MW} \pm S D)$ ) [siehe Abbildung 9]. Bei den hypertrophen Fasern war iNOS der

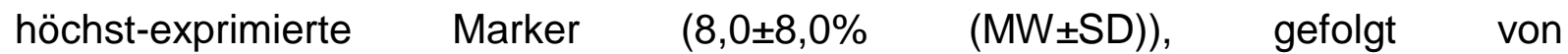
Neurofilamenten/phosphoryliertes Tau (6,8 $\pm 15,1 \%$ (MW $\pm S D))$ und aB-Crystallin $(6,8 \pm 11,6 \%(\mathrm{MW} \pm \mathrm{SD}))$ [siehe Abbildung 9]. Die anderen Marker waren weitaus geringer exprimiert. In hypertrophen Fasern war APP nicht detektierbar. IL-1 $\beta$ war sowohl in hypertrophen als auch in vakuolisierten Fasern der am geringsten exprimierte Marker $(0,5 \pm 1,7 \%$ in hypertrophen, $0,5 \pm 1,5 \%$ in vakuolisierten Fasern $(\mathrm{MW} \pm \mathrm{SD})$ ), in atrophen Fasern war er der zweit geringste exprimierte Marker $(1,5 \pm 2,6 \%(M W \pm S D))$ [siehe Abbildung 9]. Ebenso zeigte sich, dass die Anzahl atropher Fasern mit der Anzahl der aB-Crystallin-positiven Fasern signifikant und positiv korrelierte $\left({ }^{* *} \mathrm{P}<0,001 ; r=0,9206\right)$ [ohne Abbildung]. 
A

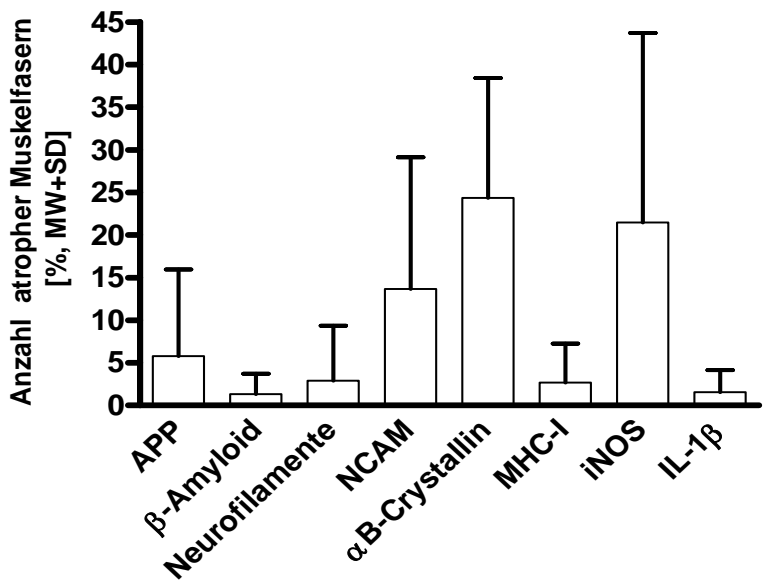

B

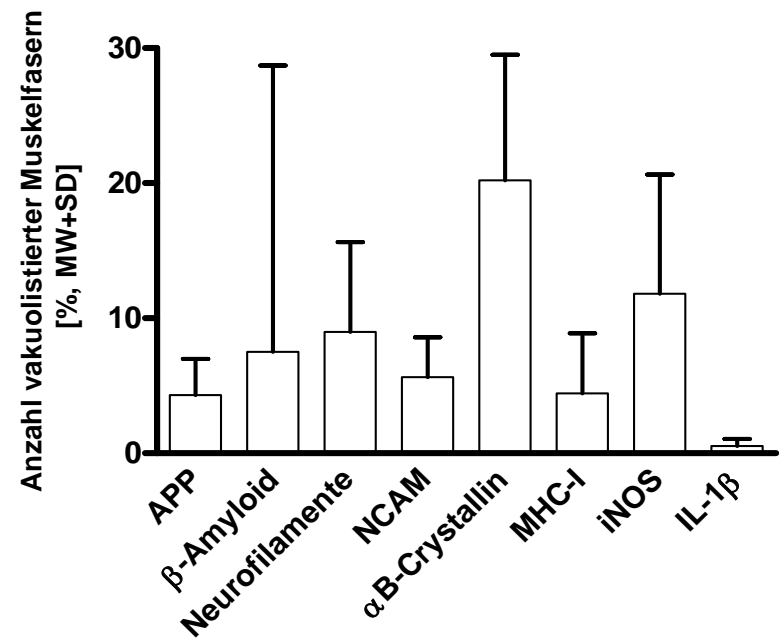

C

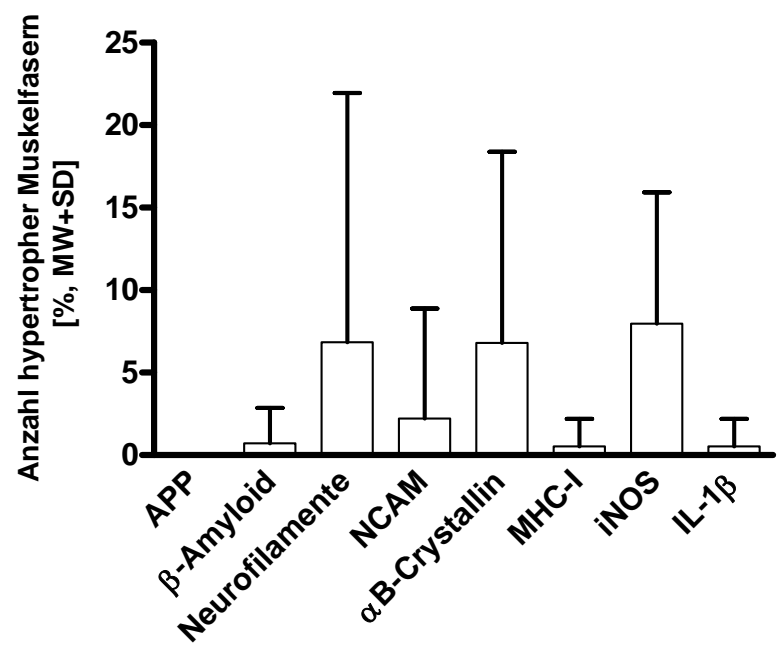

Abbildung 9: Proteinexpression von Markern für Proteinakkumulation, Entzündung und Zellstress in morphologisch auffälligen hIBM-Muskelfasern; A) die Expression in von aB-Crystallin und iNOS ist in atrophen Fasern am höchsten, $\beta$-Amyloid ist am niedrigsten exprimiert. B) die Expression von aB-Crystallin und iNOS in Fasern mit Vakuolen ist am höchsten, IL-1 $\beta$ ist am niedrigsten exprimiert. C) die Expression von iNOS und 
Neurofilamenten/phosphoryliertem Tau in hypertrophen Fasern ist am höchsten, IL-1 $\beta$ und MHC-I sind am niedrigsten exprimiert. APP ist in hypertrophen Fasern nicht detektierbar.

\subsection{Expression von Markern für Proteinakkumulation, Entzündung und Zellstress in normal erscheinenden Muskelfasern von hIBM-Patienten}

Ebenfalls wurde die Expression der untersuchten Marker für Degeneration, Entzündung und Zellstress in normal erscheinenden Muskelfasern analysiert um frühe Veränderungen in der Pathologie zu beschreiben. Eine Überexpression des Hitzeschockproteins aB-Crystallin bei normal erscheinenden sIBM-Muskelfasern wurde bereits beschrieben [Banwell und Engel 2000] und wird als frühes Zeichen für Zellstress im Pathomechanismus der sIBM gewertet. Diese Fasern, mit den Kriterien lichtmikroskopisch unauffällig und aB-Crystallin-positiv, wurden bei der sIBM als „XFasern" bezeichnet.

Bei der mikroskopischen Analyse zeigten sich ebenfalls einige morphologisch unauffällige hIBM-Fasern, die in der immunhistochemischen Untersuchung eine Überexpression von aB-Crystallin zeigten [siehe Abbildung 10]. Ebenso fielen unauffällige Fasern mit einer Überexpression von iNOS auf [siehe Abbildung 10]. 
A

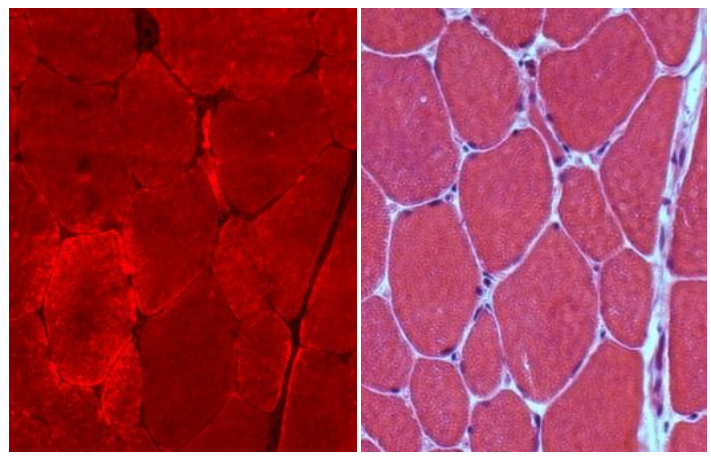

B

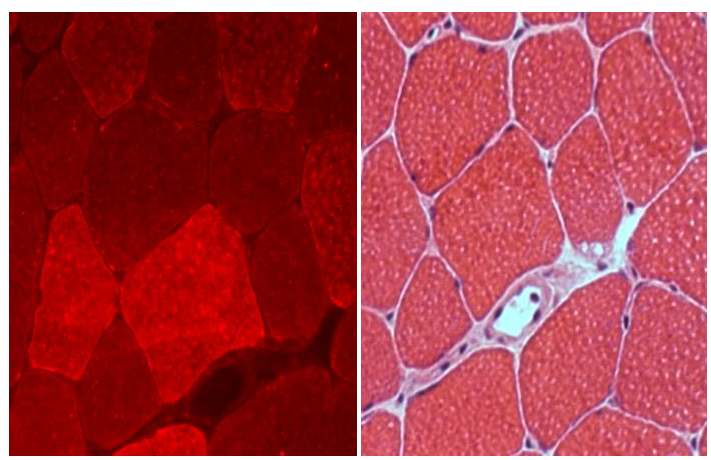

Abbildung 10: Subtypenanalyse normal erscheinender hIBM-Fasern; A) Normal erscheinende Muskelfasern in der H\&E-Färbung zeigen eine Überexpression von aBCrystallin in der immunhistochemischen Färbung, B) Normal erscheinende Muskelfasern in H\&E-Färbung zeigen eine Überexpression von iNOS in Immunhistochemischer Färbung.

Eine weitere Quantifizierung dieser morphologisch unauffälligen Fasern in der mikroskopischen Analyse zeigte, dass aB-Crystallin und iNOS die meisten positiven Fasern aufwiesen [siehe Abbildung 11]. Der Anteil an „X-Fasern“ in den daraufhin

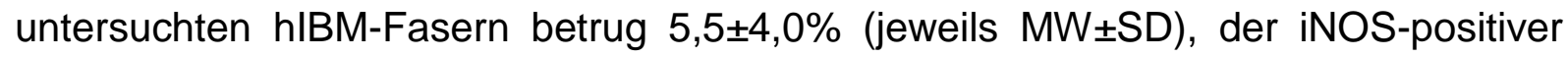
Fasern 10,8 $\pm 9,0 \%$. Die anderen untersuchten Marker waren deutlich niedriger exprimiert: APP $0,4 \pm 0,7 \%$, $\beta$-Amyloid 1,4 $1,9 \%$, Neurofilamente/phosphoryliertes

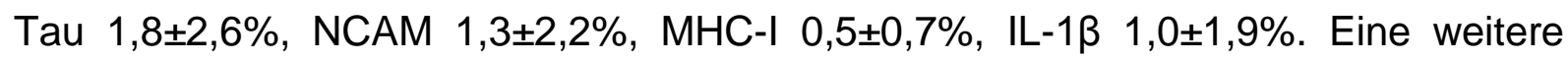
Sub-Typen-Analyse der „X-Fasern“ ergab zudem, dass 11,7\% dieser Fasern doppelt positiv für $\alpha \mathrm{B}-$ Crystallin und iNOS waren [ohne Abbildung]. 


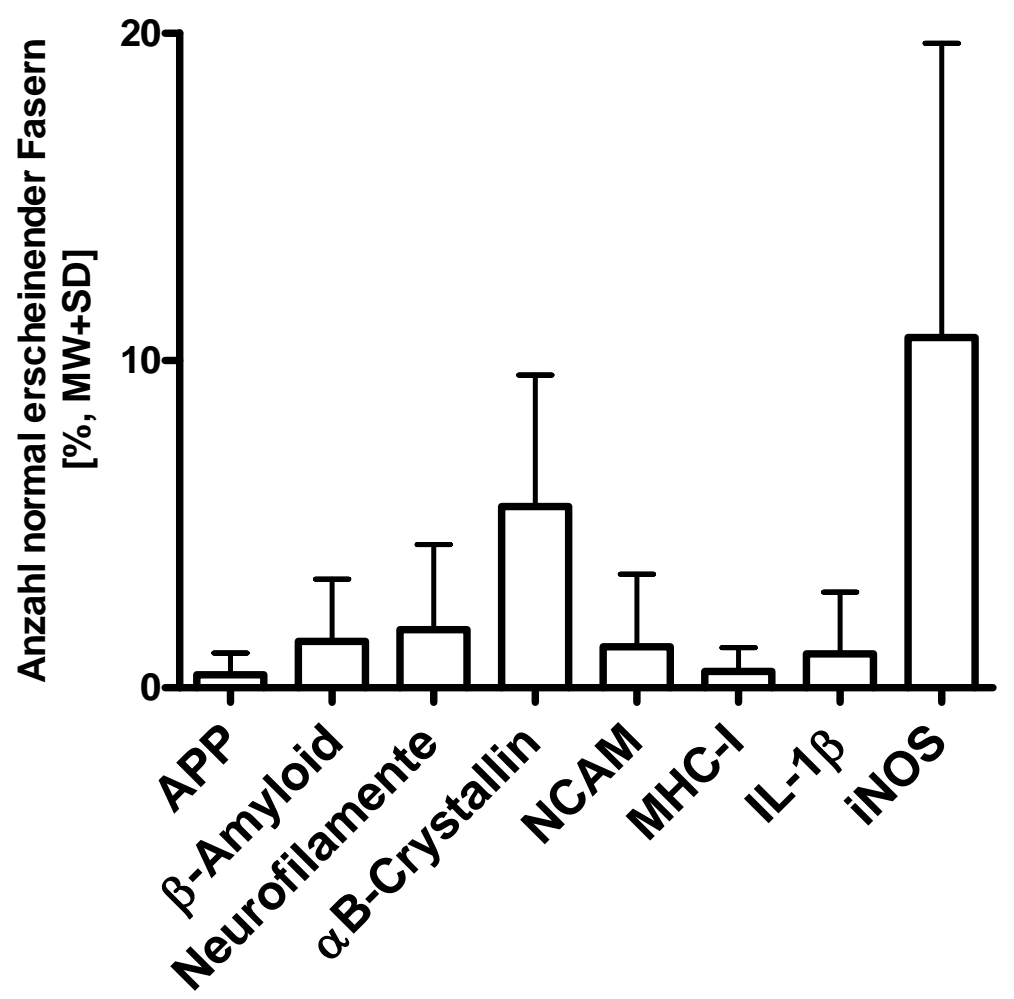

Abbildung 11: Quantifizierung morphologisch unauffälliger hIBM- Muskelfasern; in normal erscheinenden hIBM-Fasern werden aB-Crystallin und iNOS am höchsten exprimiert, die anderen Marker zeigten eine geringere Expression. 


\subsection{Geschlechtsspezifische Analyse in der Expression von Markern für Degeneration, Entzündung und Zellstress bei hIBM}

\subsubsection{Einleitung}

Die epidemiologischen Daten zur hIBM sind sehr rar und eine genaue Darstellung über die Patientenzahlen und Patientendaten ist nicht vorhanden. Daher ist eine unterschiedliche Verteilung unter den Geschlechtern, wie sie zum Beispiel bei der slBM besteht ( $m: w=2-3: 1)$ [Needham und Mastaglia 2008], nicht bekannt. Um dennoch mögliche Unterschiede zwischen den Geschlechtern zu detektieren, wurden die erhobenen Daten der mRNA-und Proteinexpression in hIBM-Muskelfasern auf unterschiedliche Expression in männlichen im Vergleich zu weiblichen Patienten untersucht. Eine solche Untersuchung wurde für die hIBM bisher nicht publiziert. Bei den zehn Muskelproben stammten vier von Männern, sechs von Frauen (siehe Teil 3: Material und Methoden); diese wurden miteinander verglichen und statistische Analysen zur Signifikanz durchgeführt.

\subsubsection{Geschlechtsspezifische mRNA-Expression}

Der Marker für Proteinakkumulation APP zeigte eine etwas höhere mRNAExpression bei Frauen gegenüber Männern (1,7fach), eine ähnliche Expression zeigte sich auch für das Hitzeschockprotein aB-Crystallin. Auch NCAM war höher bei Frauen als bei Männern exprimiert, während Desmin und MHC-I eine fast gleiche Expression aufwiesen. Insgesamt waren sämtliche pro-inflammatorische Marker bis auf iNOS und MIG tendenziell höher exprimiert bei Frauen als bei Männern. Auch Ubiquitin war leicht erhöht bei Männern [siehe Abbildung 12]. Allerdings wurde jeweils nur eine Tendenz beobachtet und keine statistische Signifikanz erreicht.

\subsubsection{Unterschiede der Proteinexpression}

Bis auf die Proteinexpression von Neurofilamenten/phosphoryliertem Tau und $\beta$ Amyloid war die Anzahl positiver Fasern sämtlicher untersuchter Marker in der immunhistochemischen Analyse bei Männern höher als bei Frauen und damit den Ergebnissen der mRNA-Analyse widersprechend [siehe Abbildung 12]. Auch hier zeigte sich keine statistische Signifikanz. 
A

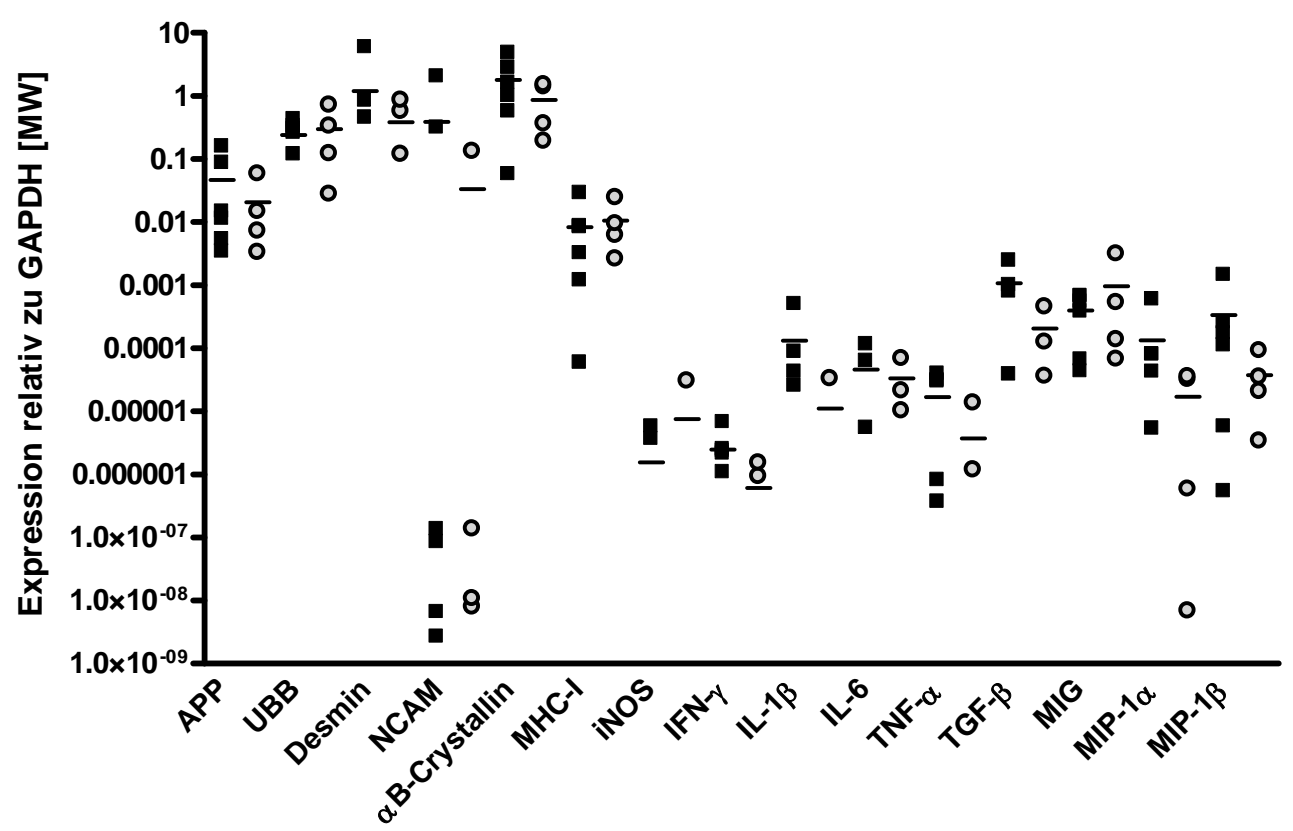

B

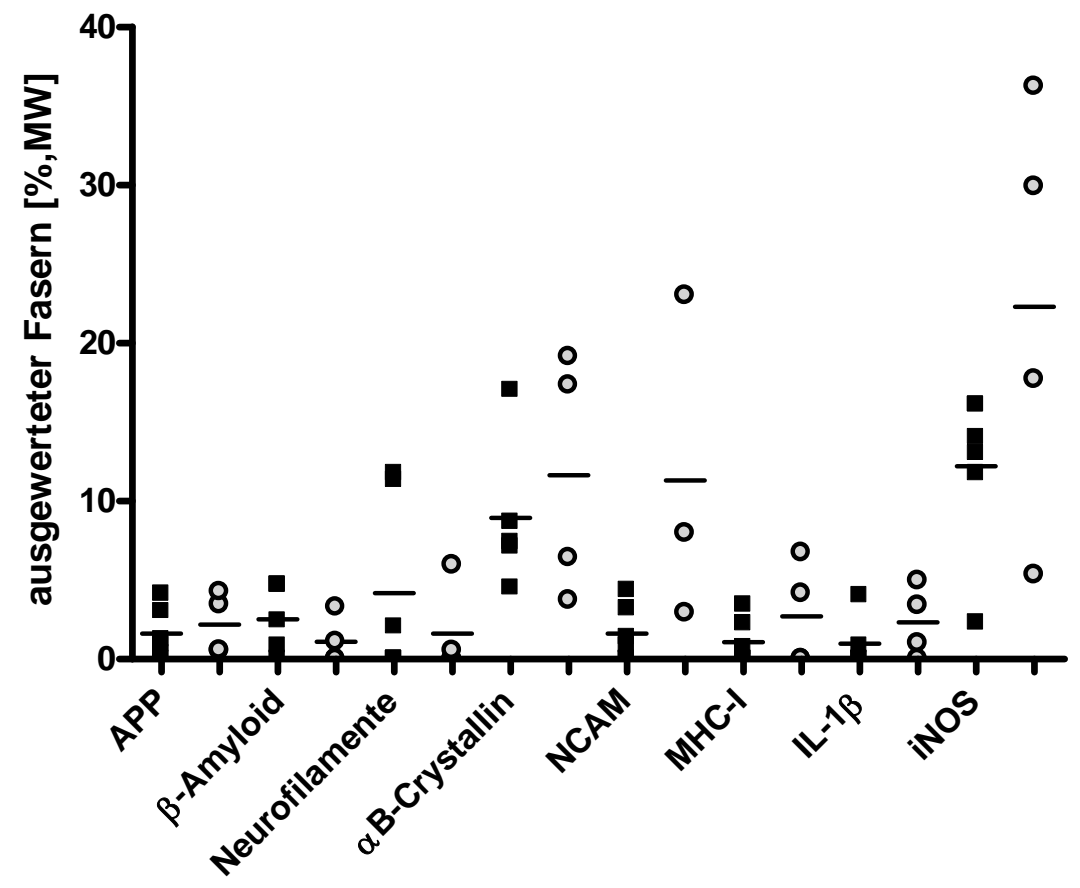

Abbildung 12: Expression der relevanten Marker bei weiblichen im Vergleich zu männlichen Patienten mit hIBM; A) zeigt die mRNA-Expression relativ zur GAPDHExpression der analysierten Marker getrennt nach Geschlecht, APP, NCAM, aB-Crystallin und pro-inflammatorische Marker sind in der Tendenz höher exprimiert bei Frauen, ohne statistische Signifikanz, B) zeigt die Proteinexpression der analysierten Marker getrennt nach Geschlecht, der Großteil der Marker ist höher exprimiert in Männern, $\beta$-Amyloid und Neurofilamenten/phosphoryliertes Tau bei Frauen. 


\subsubsection{Geschlechtsspezifische Analyse morphologischer Auffälligkeiten im hIBM-Muskel}

Die Anzahl morphologisch auffälliger Fasern war höher bei Männern, während die normal erscheinenden Fasern sich bei Frauen höher zeigten. Dies spiegelte sich auch in der Subtypenanalyse wieder; atrophe und hypertrophe Fasern waren tendenziell bei Männern mehr vertreten, vakuolisierte Fasern und „X-Fasern“ bei Frauen [siehe Abbildung 13], was jedoch keine statistische Signifikanz erreichte.

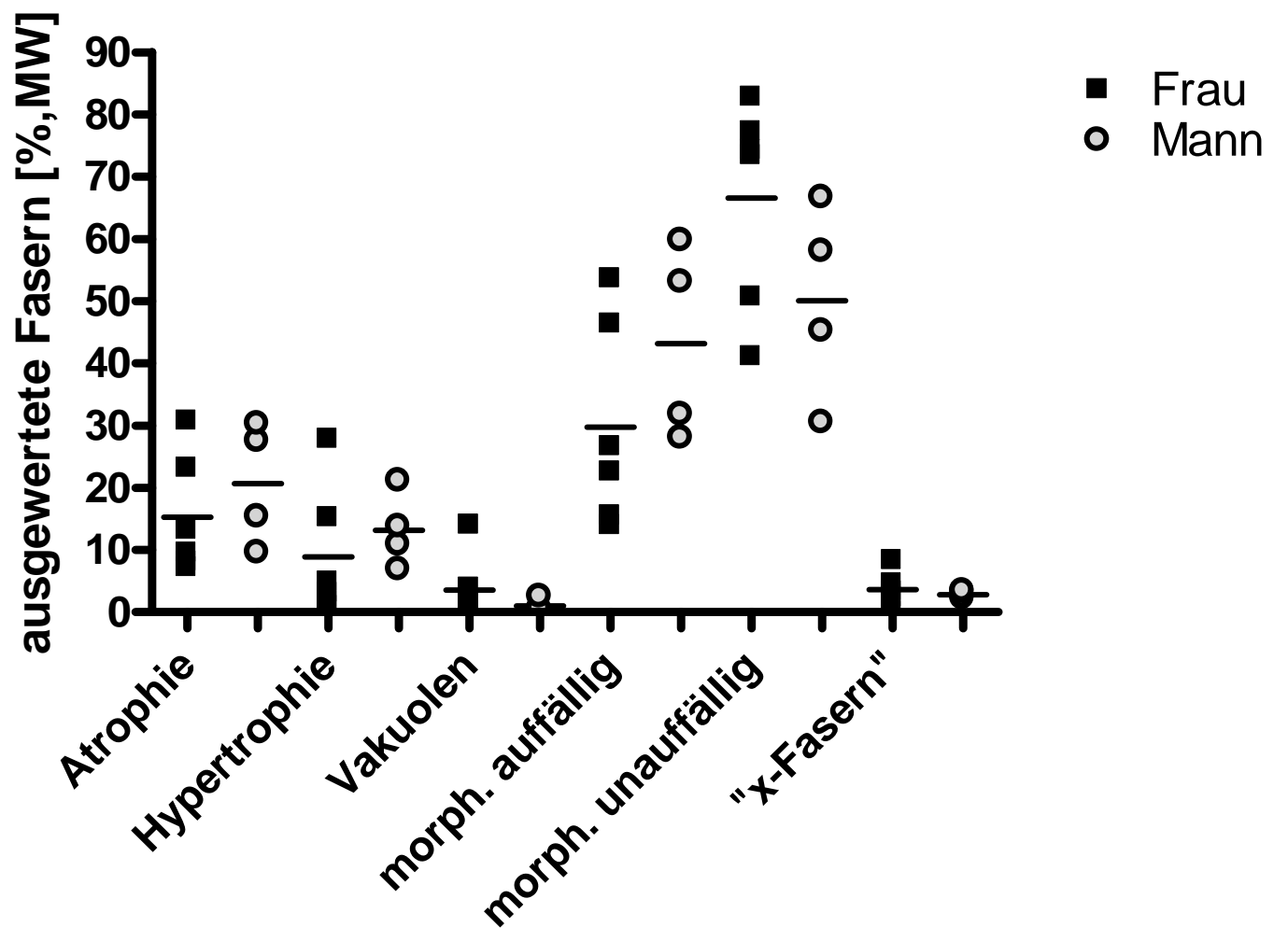

Abbildung 13: Geschlechtsspezifische Analyse morphologischer Auffälligkeiten; die Muskelfasern weiblicher Patienten zeigten eher normal erscheinende Fasern, die männlicher Patienten eher atrophische und hypertrophische Fasern und daher mehr morphologische Auffälligkeiten, die Expression von „x-Fasern“ war bei Frauen tendenziell höher. 


\section{Diskussion}

\section{1 aB-Crystallin und iNOS als frühe pathogenetische Indikatoren bei der hIBM}

Obwohl bei der hIBM die grundlegende Pathogenese durch die Mutation im GNEGen beschrieben ist, sind die Pathomechanismen, die zu der entsprechenden Muskelpathologie führen, nicht genau bekannt. Ebenso wie bei der sIBM scheint die $\beta$-Amyloid-assoziierte Degeneration darin eine zentrale Rolle zu spielen [Broccolini et al. 2009]. Darüber hinaus ist eine Beteiligung entzündlicher Pathomechanismen umstritten, eine zelluläre Infiltration wird in der Mehrzahl der Fälle zumindest nicht beobachtet [Askanas und Engel 1998]. Die Forschung konzentrierte sich in den letzten Jahren vorwiegend auf die Entschlüsselung der verschiedenen Mutationen [Halawani et al. 2009, Malicdan et al. 2007, Stober et al. 2010], ihre Auswirkungen auf zelluläre Prozesse und Pathomechanismen [Eisenberg et al. 2008, Amsili et al. 2008] und verschiedene Therapieoptionen. Hierbei steht die gentherapeutische Behandlung sowie die Substitution von Sialinsäure im Vordergrund [Malicdan et al. 2009, Nemunaitis et al. 2010]. Allerdings konzentrierten sich nur wenige Veröffentlichungen auf die spezielle Muskelpathologie und Mechanismen im Muskel selbst. Ein kürzlich beschriebener Mechanismus ist, dass NCAM als zellulärer Marker bei der hIBM hyposialisiert ist [Ricci et al. 2006, Broccolini et al. 2010]. Dies wird nun als diagnostisches Molekül diskutiert. Eine genaue quantitative Messung von NCAM oder anderen Markern im hIBM-Muskel ist allerdings noch nicht erfolgt. Auch in verschiedenen Veröffentlichungen über oxidativen Stress bei der sIBM und hIBM wurden keine quantitativen Untersuchungen gemacht [Askanas und Engel 1998, Yang et al. 1998]. In der vorliegenden Arbeit wurden erstmals auch quantitative Untersuchungen verschiedener pathologischer Marker bei der hIBM durchgeführt. Im Zentrum dieser Dissertation steht die Expression verschiedener Marker für Zellstress, Proteinakkumulation, Degeneration/Regeneration und Entzündung im Muskel von hIBM-Patienten, sowohl auf mRNA-, als auch auf Proteinebene.

Es ist bekannt, dass APP-Überexpression in vitro die Expression des Hitzeschockproteins aB-Crystallin signifikant erhöht [Wojcik et al. 2006]. Ebenso konnte durch immunhistochemische Techniken eine erhöhte Ko-Lokalisation von APP/ $\beta$-Amyloid und $\alpha B-C r y s t a l l i n$ demonstriert werden. Es wird angenommen, dass $\alpha B-C r y s t a l l i n$ als Antwort auf die Bildung von APP/ $\beta$-Amyloid hochreguliert wird. 
In dieser Arbeit konnte eine Überexpression des Proteins aB-Crystallin demonstriert werden, sowohl in normal erscheinenden Fasern als auch in strukturell auffälligen Fasern. Eine Überexpression des Hitzeschockproteins in normal erscheinenden Fasern wurde bisher nur bei der sIBM beschrieben [Banwell und Engel 2000, Muth et al. 2009] und diese Fasern wurden als „x-Fasern“ benannt. Die vorliegende Arbeit konnte erstmals zeigen, dass bei der hIBM ebenfalls „x-Fasern“ mit einer mittleren Prozentzahl von 5,5\% vorhanden sind. Damit sind sie geringer vorhanden als bei der sIBM. Eine mögliche Erklärung wäre, dass eine zelluläre Entzündungsreaktion bei der hIBM im Gegensatz zur sIBM nicht vorliegt. Pro-inflammatorischer Zellstress, der auch unabhängig von Entzündungszellen vorliegen kann, begünstigt die Expression von aB-Crystallin in vitro in Muskelzellen [Muth et al. 2009]. Ebenso wird die aBCrystallin-Expression in vitro durch die Expression von $A P P / \beta-A m y l o i d$ beeinflusst [siehe oben]. Es konnte zwar eine Ko-Lokalisation von APP und $\beta$-Amyloid mit $\alpha B$ Crystallin in hIBM-Muskelfasern nachgewiesen werden, allerdings zeigte sich eine weitaus geringere Expression von APP und $\beta$-Amyloid in den untersuchten Proben als bei der sIBM [Muth et al. 2009]. Ebenso ist aB-Crystallin im Vergleich zu quantitativen Studien der sIBM weitaus geringer exprimiert [Muth et al. 2009].

Eine weitere wesentliche Beobachtung ist die Überexpression von iNOS, welches in morphologisch auffälligen Fasern der hIBM als überexprimiert gilt [Yang et. al. 1998], was auch in dieser Arbeit bestätigt werden konnte. Darüber hinaus konnte in der vorliegenden Arbeit erstmals demonstriert werden, dass iNOS ebenso in morphologisch unauffälligen Fasern überexprimiert wird und damit ebenso wie die Expression von aB-Crystallin ein frühes pathologisches Ereignis im Krankheitsverlauf zu sein scheint. Ebenso wurde eine signifikante Korrelation der beiden Marker auf der Proteinebene und eine erhöhte Ko-Lokalisation von iNOS und aB-Crystallin in normal erscheinenden Fasern gesehen, was eine gleichsinnige Mitwirkung an der Pathologie vermuten lässt. Somit können sowohl aB-Crystallin als auch iNOS als frühe pathologische Marker bei der hIBM angesehen werden, was bisher nicht bekannt gewesen ist.

\subsection{Pro-inflammatorische Pathomechanismen bei der hIBM}

Im Gegensatz zur sIBM zählt die hIBM nicht zu den inflammatorischen Myopathien und ausgeprägte entzündliche Infiltrationen werden nicht beobachtet [Askanas et 
al.1993]. Die genauen Pathomechanismen bleiben nur unzureichend geklärt, wobei bis auf die Entzündung eine ähnliche Muskelpathologie bei beiden gesehen wird. Eine mögliche Erklärung ist die bei beiden Erkrankungen bestehende abnormale Akkumulation von APP/ß-Amyloid [Askanas et al. 1993] und Tau-Proteinen [Mirabella et al. 1996], sowie einigen anderen Markern.

In der vorliegenden Arbeit konnte gezeigt werden, dass die mRNA-Expression von aB-Crystallin und APP mit einer Reihe pro-entzündlicher Marker korrelierte. Ähnliche Ergebnisse zeigten auch Untersuchungen zur sIBM [Schmidt et al. 2008], bei der pro-inflammatorische Pathomechanismen bekannt sind [Carpenter et al. 1978]. Dies lässt eine entzündliche Komponente in der Pathologie der hIBM vermuten, auch ohne dass eine zelluläre Infiltration nachweisbar ist.

Darüber hinaus zeigte sich in der vorliegenden Arbeit auf immunhistochemischer Ebene, dass die Fasern, die positiv waren für aB-Crystallin, MHC-I, iNOS und NCAM, jeweils signifikant miteinander korrelieren, und dass eine Ko-Lokalisation von aB-Crystallin mit MHC-I, iNOS und NCAM besteht. Dieses stützt zum einen die Ergebnisse der mRNA-Analyse bei der hIBM und ist zum anderen auch analog zu der Ko-Lokalisation von aB-Crystallin mit MHC-I und NCAM bei der sIBM [Ferrer et al. 2004, Muth et al. 2009]. Dieses stützt zusätzlich die These einer proinflammatorischen und zellstress-assoziierten Komponente als Pathomechanismus der hIBM, was ähnlich der sIBM ablaufen könnte (siehe oben). Dieses würde auch die ähnliche Muskelpathologie bei beiden Erkrankungen erklären können. Allerdings konnten entzündliche Infiltrate wie bei der sIBM in dieser Arbeit nicht gezeigt werden, was im Einklang mit vorhergehenden Veröffentlichungen steht [Yabe et al. 2003]. Somit sind im Gegensatz zur sIBM bei der hIBM pro-inflammatorische Mechanismen zu diskutieren, die auf die Muskelfaser lokalisiert bleiben.

\subsection{Einfluss von aB-Crystallin auf die Morphologie des Muskels von Patienten mit hIBM}

Typische Kennzeichen des hIBM-Muskels sind $u$. a. die Bildung vakuolisierter und atropher Fasern im Krankheitsverlauf [Broccolini et al. 2009]. Wie genau es zu der Entstehung dieser charakteristischen Morphologie kommt, ist allerdings bisher unzureichend verstanden. Im Mausmodell der hIBM konnte die Muskelpathologie als Folge der GNE-Mutation nachgewiesen werden [Malicdan et al. 2007], allerdings 
kommt es auch bei der sIBM, bei der GNE-Mutationen nicht vorliegen, zur Ausbildung derselben Muskelpathologie. Dieses lässt andere Faktoren als Ursache der Entstehung vermuten.

Es konnte gezeigt werden, dass die Muskelatrophie im Mausmodell der hIBM sowohl in vivo als auch ex vivo mit der Muskelschwäche signifikant korrelierte [Malicdan et al. 2008] und damit ein wichtiges pathologisches Ereignis im Krankheitsverlauf darstellt.

Durch die Entdeckung der „X-fibres“ bei der sIBM (siehe oben) durch Banwell und Engel wird vermutet, dass aB-Crystallin ebenfalls eine pathogenetische Bedeutung haben könnte. Diese These wird durch die Beobachtungen dieser Arbeit auf die

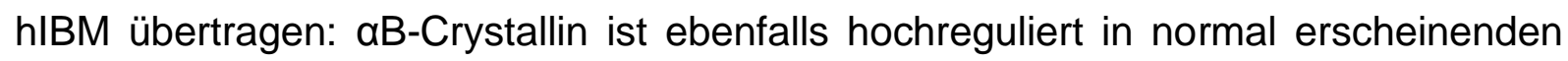
Muskelfasern sowie in atrophen, hypertrophen und vakuolisierten Fasern. Es konnte sogar eine signifikante Korrelation zwischen atrophen und aB-Crystallin-positiven Fasern demonstriert werden. Damit ist eine zentrale Rolle von aB-Crystallin bei der morphologischen Veränderung im hIBM-Muskel ebenfalls anzunehmen.

Die Muskelfasergröße wird durch ein Gleichgewicht zwischen Proteinabbau und -aufbau in der Muskelfaser definiert und wenn es zu einer Verschiebung dessen kommt, also zu einem vermehrten Abbau der Proteine, wird die Muskelfaser atroph. Dieses kommt auch physiologisch im Alter, bei fehlender muskulärer Beanspruchung oder als Zeichen pathologischer Veränderungen bei verschiedenen Erkrankungen vor. Dementsprechend existieren auch verschiedene mögliche Mechanismen, die zur Muskelatrophie führen.

Beim Beispiel der Muskelatrophie auf Grund muskulärer Entlastung wurden allerdings erhöhte aB-Crystallin-Werte im atrophen Muskel nach kurzzeitigem Training beobachtet [Gwag et al. 2009]. Dieses führt zu der Überlegung, ob aBCrystallin eventuell in der anabolen Stoffwechsellage eine zentrale Rolle spielt. Im Rahmen der IBM-Forschung könnte aB-Crystallin daher Teil einer fehlgeleiteten Regeneration sein. Somit stellen die vorliegenden Daten einen wesentlichen Beitrag zu dessen Verständnis der Pathologie der hIBM dar 


\subsection{Einfluss des Geschlechts auf die Muskelpathologie bei der hIBM}

Daten zu einem unterschiedlichen Krankheitsverlauf, bzw. zu einer unterschiedlichen Erkrankungshäufigkeit bei Männern im Vergleich zu Frauen existieren bei der hIBM zum heutigen Zeitpunkt nicht. Dies liegt auch an der geringen Anzahl erkrankter Personen weltweit. Da der Erbgang autosomal verläuft [Needham et al. 2007], kann eine gleiche Verteilung der Erkrankung bei beiden Geschlechtern angenommen werden, auch wenn dazu keine Daten bestehen. Anders verhält es sich bei der sIBM, wo eine Ungleichverteilung zugunsten der Männer ( $m: w=2-3: 1)$ besteht [Needham und Mastaglia 2008], welche sich allerdings bis heute nicht erklären lässt.

Dennoch macht es Sinn auf mögliche Unterschiede in der Muskelpathologie zu schauen, da auch geschlechtsspezifische Faktoren Einfluss auf den Erkrankungsverlauf haben können. In der vorliegenden Arbeit konnten unterschiedliche Tendenzen sowohl in der mRNA-Expression von Markern für Proteinakkumulation, Degeneration/Regeneration, Entzündung und Zellstress, als auch in der Proteinexpression und Muskelmorphologie bei männlichen und weiblichen hIBM-Patienten demonstriert werden. Dies lässt sich z.B. durch die unterschiedliche Verteilung von Sexualhormonen erklären.

Myoblasten, Myotuben und auch reife Muskelfasern exprimieren funktionelle Östrogenrezeptoren und Östrogen stimuliert Transkriptionsfaktoren in proliferierenden Myoblasten [Kahlert et al. 1997]. Es ist zudem eine häufige Beobachtung, dass Frauen in der Menopause einen Abfall der Muskelmasse bekommen. Genauer wird ein Zusammenhang zwischen dem Absinken des Östrogens und Muskelatrophie angenommen [Maltais et al. 2009]. Dieses würde die Ergebnisse der vorliegenden Arbeit stützen, in der eine deutliche höhere Anzahl atropher Fasern bei den Muskelbiopsieproben der männlichen hIBM-Patienten gesehen wurde. Zudem ist bekannt, dass Östrogen einen positiven Einfluss auf Muskelregeneration sowie die Aktivierung von Muskel-Satelliten-Zellen hat [Enns und Tiidus 2010]. Dies könnte erklären, warum die Anzahl der morphologisch unauffälligen Fasern ebenso wie die der x-Fasern bei den weiblichen hIBM-Patienten deutlich höher ist, als bei den männlichen. Eine mögliche Protektion der Muskelmorphologie durch weibliche Steroidhormone könnte für den Krankheitsverlauf der hIBM relevant sein. 
Eine höhere mRNA-Expression aller wichtigen pro-inflammatorischen Zytokine bei den weiblichen hIBM-Patienten könnte sich ebenfalls durch die erhöhte Östrogenkonzentration bei den Frauen erklären. Generell wird für die weiblichen Sexualhormone eher eine immunstimulierende Wirkung und für Androgene eher eine immunsuppressive Wirkung beschrieben [Lahita 1993]. Ebenso konnte demonstriert werden, dass Östrogene, nicht aber Androgene, die Synthese des wichtigen proinflammatorischen Zytokins TNF- $\alpha$ in menschlichen Monoblasten steigern [Carruba et al. 2003]. Hindurch könnte erklären, warum die mRNA-Expression fast sämtlicher pro-inflammatorischer Zytokine bei den weiblichen hIBM-Patienten höher ist als bei den männlichen. Es wiederspricht allerdings den Daten der immunhistochemischen Färbungen und der H\&E-Färbung, bei denen die Anzahl der Fasern positiv für pathologische Marker und morphologische Auffälligkeiten bei Frauen mehrheitlich geringer ist als bei Männern.

Lediglich die Anzahl an Fasern mit Vakuolen war bei Frauen gegenüber Männern bei der hIBM leicht erhöht, was sich auch auf die Daten der immunhistochemischen Färbungen stützt. Hier zeigte sich, dass die Anzahl an Fasern positiv für Neurofilamente bei Frauen höher ist als bei Männern.

Insgesamt wäre es sehr interessant, epidemiologische Daten zu einem unterschiedlichen Krankheitsverlauf bei Männern und Frauen bei der hIBM zu erheben und zu prüfen, ob sie auf die Beobachtungen der Muskelpathologie und mRNA-Expression aufbauen können. 


\section{Zusammenfassung}

Die hIBM ist eine chronisch progrediente Muskelerkrankung, die durch eine Mutation im GNE-Gen bedingt wird und im Verlauf zu einer Muskelatrophie und Muskelschwäche führt. Die Charakteristika der Muskelpathologie beinhalten die Bildung von vakuolisierten und atrophen Fasern, sowie die abnormale Akkumulation verschiedener degenerativer Marker-Proteine wie $\beta$-Amyloid und sein Vorläuferprotein APP sowie das Tau-Protein. Im Gegensatz zur sIBM sind entzündliche Pathomechanismen bisher nicht bekannt und eine zelluläre Entzündung wird im hIBM-Muskel nicht beobachtet. Insgesamt sind die Pathomechanismen der hIBM sehr komplex und nicht genau verstanden. Dieses Unverständnis trägt oft zu einer unsicheren Diagnosestellung bei und es gibt bis heute keine effektive Therapie für diese Erkrankung.

Ziel dieser Arbeit war es, eine quantitative Analyse verschiedener Marker für Proteinakkumulation, Degeneration/Regeneration, Entzündung und Zellstress an humanen hIBM-Muskelbiopsien durchzuführen. Die Expression wurde sowohl auf mRNA- als auch auf Proteinebene durch quantitative PCR und immunhistochemische Färbungen analysiert.

Die Daten der mRNA-Analyse konnten keine signifikant erhöhte mRNA-Expression der untersuchten Marker bei der hIBM im Vergleich zu nicht-myopathischen Kontrollen zeigen. Die mRNA-Expressionen der degenerativen Marker APP und aBCrystallin korrelierte jedoch signifikant mit wichtigen Markern für Entzündung. Ebenso ko-lokalisierten und korrelierten die Fasern, die positiv für aB-Crystallin, NCAM, MHC-I und iNOS waren, signifikant miteinander. Zudem konnte eine aB-CrystallinÜberexpression in normal erscheinenden Fasern, wie bisher nur bei der sIBM beobachtet, nachgewiesen werden. Dieses Hitzeschockprotein zeigte sich auch als überexprimiert in morphologisch auffälligen Fasern. Ebenso zeigte sich der zellstress-assoziierte Marker iNOS als überexprimiert sowohl in morphologisch unauffälligen, als auch in morphologisch auffälligen Fasern. Zudem konnte in dieser Arbeit eine erhöhte Ko-Lokalisation von iNOS und aB-Crystallin in normal erscheinenden Fasern demonstriert werden.

Eine Untersuchung auf geschlechtsspezifische Unterschiede in der mRNA- und Protein-Expression pathologischer Marker zeigte einen Trend für eine erhöhte mRNA-Expression pro-inflammatorischen Marker bei Frauen, hingegen war die 
Proteinexpression fast sämtlicher untersuchter Marker höher bei den männlichen Patienten. Ebenso zeigten Frauen im Vergleich zu Männern weniger pathomorphologische Merkmale der Muskelfasern.

Zusammenfassend weisen diese Ergebnisse auf eine frühe Zellstress-Antwort im hIBM-Muskel hin, die der im sIBM-Muskel ähnlich ist und eine pro-inflammatorische Komponente ohne zelluläre Infiltration als Pathomechanismus der hIBM nahelegen. Dies könnte sowohl für die diagnostischen als auch therapeutischen Möglichkeiten in Zukunft als Ansatzpunkt dienen. 


\section{Literaturverzeichnis}

Adler R S, Garolfalo G, Paget S, Kagen L (2008): Muscle sonography in six patients with hereditary inclusion body myopathy. Skeletal Radiol $\underline{37}$, 43-48.

Ahlberg G, von Tell D, Borg K, Edström L, Anvret M (1999): Genetic linkage of Welander distal myopathy to chromosome 2p13. Ann Neurol $\underline{46}$, 399-404.

Amsili S, Zer H, Hinderlich S, Krause S, Becker-Cohen M, MacArthur D G, North K N, Mitrani-Rosenbaum S (2008): UDP-N-acetylglucosamine 2-epimerase/Nacetylmannosamine kinase (GNE) binds to alpha-actinin 1: novel pathways in skeletal muscle? PLoS One $\underline{3}, 2477$.

Arai A, Tanaka K, Ikeuchi T, Igarashi S, Kobayashi H, Asaka T, Date H, Saito M, Tanaka H, Kawasaki $S$ et al. (2002): A novel mutation in the GNE gene and a linkage disequilibrium in Japanese pedigrees. Ann Neurol $\underline{52}, 516-519$.

Argov Z, Yarom R (1984): "Rimmed vacuole myopathy" sparing the quadriceps. A unique disorder in Iranian Jews. J Neurol Sci $\underline{64}$, 33-43.

Askanas V, Engel W K (1993): New advances in inclusion-body myositis. Curr Opin Rheumatol $\underline{5}, 732-741$.

Askanas V, Engel W K (1998): Sporadic inclusion-body myositis and its similarities to Alzheimer disease brain. Recent approaches to diagnosis and pathogenesis, and relation to aging. Scand J Rheumatol $\underline{27}$, 389-405.

Askanas V, Serdaroglu P, Engel W K, Alvarez R B (1991): Immunolocalization of ubiquitin in muscle biopsies of patients with inclusion body myositis and oculopharyngeal muscular dystrophy. Neurosci Lett 130, 73-76.

Askanas V, Alvarez R B, Engel W K (1993): beta-Amyloid precursor epitopes in muscle fibers of inclusion body myositis. Ann Neurol 34, 551-560.

Askanas V, Engel W K, Nogalska A (2009): Inclusion body myositis: a degenerative muscle disease associated with intra-muscle fiber multi-protein aggregates, proteasome inhibition, endoplasmic reticulum stress and decreased lysosomal degradation. Brain Pathol $\underline{19}$, 493-506.

Banwell B L, Engel A G (2000): AlphaB-crystallin immunolocalization yields new insights into inclusion body myositis. Neurology $\underline{54}, 1033-1041$.

Baron P, Galimberti D, Meda L, Prat E, Scarpini E, Conti G, Moggio M, Prelle A, Scarlato $G$ (2000): Synergistic effect of beta-amyloid protein and interferon gamma on nitric oxide production by $\mathrm{C} 2 \mathrm{C} 12$ muscle cells. Brain $\underline{123}, 374-379$. 
Baron P, Galimberti D, Meda L, Scarpini E, Conti G, Cogiamanian F, Scarlato G (2001): Production of IL-6 by human myoblasts stimulated with Abeta: relevance in the pathogenesis of IBM. Neurology $\underline{57}, 1561-1565$.

Bennardini F, Wrzosek A, Chiesi M (1992): Alpha B-crystallin in cardiac tissue. Association with actin and desmin filaments. Circ Res $\underline{71}$, 288-294.

Broccolini A, Gliubizzi C, Pavoni E, Gidaro T, Morosetti R, Sciandra F, Giardina B, Tonali P, Ricci E, Brancaccio A et al.(2005): alpha-Dystroglycan does not play a major pathogenic role in autosomal recessive hereditary inclusion-body myopathy. Neuromuscul Disord 15, 177-184..

Broccolini A, Gidaro T, De Cristofaro R, Morosetti R, Gliubizzi C, Ricci E, Tonali P A, Mirabella M (2008): Hyposialylation of neprilysin possibly affects its expression and enzymatic activity in hereditary inclusion-body myopathy muscle. J Neurochem $\underline{105}$, 971-981.

Broccolini A, Gidaro T, Morosetti R, Mirabella M (2009): Hereditary inclusion-body myopathy: clues on pathogenesis and possible therapy Muscle Nerve $\underline{40}$, 340-349

Broccolini A, Gidaro T, Tasca G, Morosetti R, Rodolico C, Ricci E, Mirabella M (2010): Analysis of NCAM helps identify unusual phenotypes of hereditary inclusionbody myopathy. Neurology $\underline{75}, 265-272$.

Carpenter S, Karpati G, Heller I, Eisen A (1978): Inclusion body myositis: a distinct variety of idiopathic inflammatory myopathy. Neurology $\underline{28}$, 8-17.

Carruba G, D'Agostino P, Miele M, Calabrò M, Barbera C, Di Bella G, Milano S, Ferlazzo V, Caruso R, La Rosa M et al. (2003): Estrogen regulates cytokine production and apoptosis in PMA-differentiated, macrophage-like U937 cells. J Cell Biochem 90, 187-196.

Chevrel G, Granet C, Miossec P (2005): Contribution of tumour necrosis factor alpha and interleukin (IL) 1beta to IL6 production, NF-kappaB nuclear translocation, and class I MHC expression in muscle cells: in vitro regulation with specific cytokine inhibitors. Ann Rheum Dis $\underline{64}$, 1257-1262.

Chung K F (2005): Inflammatory mediators in chronic obstructive pulmonary disease Curr Drug Targets. Inflamm Allergy 4, 619-625.

Civatte M, Bartoli C, Schleinitz N, Chetaille B, Pellissier J F, Figarella-Branger D (2005): Expression of the beta chemokines CCL3, CCL4, CCL5 and their receptors in idiopathic inflammatory myopathies. Neuropathol Appl Neurobiol $\underline{31}, 70-79$

Dalakas M C (1992): Clinical, immunopathologic, and therapeutic considerations of inflammatory myopathies. Clin Neuropharmacol $\underline{15}, 327-351$. 
De Paepe B, Z Racz G, Schröder J M, De Bleecker J L (2004): Expression and distribution of the nitric oxide synthases in idiopathic inflammatory myopathies. Acta Neuropathol 108, 37-42.

De Paepe B, Creus K K, Bleecker J L De (2009): Role of cytokines and chemokines in idiopathic inflammatory myopathies Curr Opin Rheumatol 21, 610-616.

Di Blasi C, Mora M, Pareyson D, Farina L, Sghirlanzoni A, Vignier N, Blasevich F, Cornelio F, Guicheney P, L. Morandi (2000): Partial laminin alpha2 chain deficiency in a patient with myopathy resembling inclusion body myositis. Ann Neurol $\underline{47}, 811$ 816.

Dinarello C A (1996) Biologic basis for interleukin-1 in disease. Blood 87, 2095-2147.

Dinarello C A (2005): Blocking IL-1 in systemic inflammation. J Exp Med 201,13551359.

Eisenberg I, Avidan N, Potikha T, Hochner H, Chen M, Olender T, Barash M, Shemesh M, Sadeh M, Grabov-Nardini G et al. (2001): The UDP-Nacetylglucosamine 2-epimerase/ $\mathrm{N}$-acetylmannosamine kinase gene is mutated in recessive hereditary inclusion body myopathy. Nat Genet $\underline{29}$, 83-87.

Eisenberg I, Grabov-Nardini G, Hochner H, Korner M, Sadeh M, Bertorini T, Bushby K, Castellan C, Felice K, Mendell J et al. (2003): Mutations spectrum of GNE in hereditary inclusion body myopathy sparing the quadriceps. Hum Mutat 21, 99106.

Eisenberg I, Novershtern N, Itzhaki Z, Becker-Cohen M, Sadeh M, Willems P H G M, Friedman N, Koopman W J H, Mitrani-Rosenbaum S (2008): Mitochondrial processes are impaired in hereditary inclusion body myopathy. Hum Mol Genet 17, 3663-3674.

Emslie-Smith A M, Arahata K, Engel A G (1989): Major histocompatibility complex class I antigen expression, immunolocalization of interferon subtypes, and $\mathrm{T}$ cellmediated cytotoxicity in myopathies. Hum Pathol 20, 224-231.

Enns D L, Tiidus P M (2010): The influence of estrogen on skeletal muscle: sex matters. Sports Med $\underline{40}$, 41-58.

Farber J M (1990): A macrophage mRNA selectively induced by gamma-interferon encodes a member of the platelet factor 4 family of cytokines. Proc Natl Acad Sci USA $\underline{87}, 5238-5242$.

Ferrer I, Martín B, Castaño J G, Lucas J J, Moreno D, Olivé M (2004): Proteasomal expression, induction of immunoproteasome subunits, and local MHC class I presentation in myofibrillar myopathy and inclusion body myositis. J Neuropathol Exp Neurol 63, 484-498. 
Fratta P, Engel W K, Van Leeuwen F W, Hol E M, Vattemi G, Askanas V (2004): Mutant ubiquitin UBB+1 is accumulated in sporadic inclusion-body myositis muscle fibers. Neurology $\underline{63}, 1114-1117$.

Griggs R C, Askanas V, DiMauro S, Engel A, Karpati G, Mendell J R, Rowland L P (1995): Inclusion body myositis and myopathies. Ann Neurol 38, 705-713.

Gwag T, Lee K, Ju H, Shin H, Lee J-W, Choi I (2009): Stress and signaling responses of rat skeletal muscle to brief endurance exercise during hindlimb unloading: a catch-up process for atrophied muscle. Cell Physiol Biochem 24, 537546.

Halawani D, LeBlanc A C, Rouiller I, Michnick S W, Servant M J, Latterich M (2009): Hereditary inclusion body myopathy-linked p97/NCP mutations in the NH2 domain and the D1 ring modulate p97/VCP ATPase activity and D2 ring conformation. Mol Cell Biol $\underline{29}$, 4484-4494.

Hinderlich S, Salama I, Eisenberg I, Potikha T, Mantey L R, Yarema K J, Horstkorte R, Argov Z, Sadeh M, Reutter W et al. (2004): The homozygous M712T mutation of UDP-N-acetylglucosamine 2-epimerase/ $\mathrm{N}$-acetylmannosamine kinase results in reduced enzyme activities but not in altered overall cellular sialylation in hereditary inclusion body myopathy. FEBS Lett $\underline{566}, 105-109$.

Irving S G, Zipfel P F, Balke J, McBride O W, Morton C C, Burd P R, Siebenlist U, Kelly K (1990): Two inflammatory mediator cytokine genes are closely linked and variably amplified on chromosome 17q. Nucleic Acids Res $\underline{18}$, 3261-3270.

Jay C M, Levonyak N, Nemunaitis G, Maples P B, Nemunaitis J (2009): Hereditary Inclusion Body Myopathy (HIBM2). Gene Regul Syst Biol $\underline{3}, 181-190$.

Jayaraman M, Kannayiram G, Rajadas J (2008): Amyloid toxicity in skeletal myoblasts: Implications for inclusion-body myositis Arch Biochem Biophys 474, 1521.

Jones S A (2005): Directing transition from innate to acquired immunity: defining a role for IL-6. J Immunol 175, 3463-3468.

Kahlert S, Grohé C, Karas R H, Löbbert K, Neyses L, Vetter H (1997): Effects of estrogen on skeletal myoblast growth. Biochem Biophys Res Commun 232, 373-378.

Keppler O T, Hinderlich S, Langner J, Schwartz-Albiez R, Reutter W, Pawlita M (1999): UDP-GlcNAc 2-epimerase: a regulator of cell surface sialylation. Science $\underline{284}, 1372-1376$.

Lahita R G (1993): Sex hormones as immunomodulators of disease. Ann N Y Acad Sci $\underline{685}, 278-287$

Lazarides E, Hubbard B D (1976): Immunological characterization of the subunit of the 100 A filaments from muscle cells. Proc Natl Acad Sci U S A $\underline{73}$, 4344-4348. 
Li Y P, Chen Y, John J, Moylan J, Jin B, Mann D L, Reid M B (2005): TNF-alpha acts via p38 MAPK to stimulate expression of the ubiquitin ligase atrogin1/MAFbx in skeletal muscle. FASEB J $\underline{19}$, 362-370.

Löffler G, Petrides P E, Heinrich P C: Biochemie\& Pathobiochemie, 8. Auflage; Springer Medizin Verlag, Heidelberg 2007

Lotz B P, Engel A G, Nishino H, Stevens J C, Litchy W J (1989): Inclusion body myositis.Observations in 40 patients. Brain 112, 727-747.

Lundberg I E (2000): The role of cytokines, chemokines, and adhesion molecules in the pathogenesis of idiopathic inflammatory myopathies. Curr Rheumatol Rep 2 2, 216224.

Lundberg I E, Ulfgren A K, Nyberg P, Andersson U, Klareskog L (1997): Cytokine production in muscle tissue of patients with idiopathic inflammatory myopathies. Arthritis Rheum 므, 865-874.

Lyons G E, Moore R, Yahara O, Buckingham M E, Walsh F S (1992): Expression of NCAM isoforms during skeletal myogenesis in the mouse embryo. Dev Dyn 194, 94104.

Malicdan M C, Noguchi S, Nonaka I, Hayashi Y K, Nishino I (2007): A Gne knockout mouse expressing human GNE D176V mutation develops features similar to distal myopathy with rimmed vacuoles or hereditary inclusion body myopathy. Hum Mol Genet 16, 2669-2682.

Malicdan M C, Noguchi S, Hayashi Y K, Nishino I (2008): Muscle weakness correlates with muscle atrophy and precedes the development of inclusion body or rimmed vacuoles in the mouse model of DMRV/hIBM. Physiol Genomics 35, 106115.

Malicdan M C, Noguchi S, Hayashi Y K,Nonaka I, Nishino I (2009): Prophylactic treatment with sialic acid metabolites precludes the development of the myopathic phenotype in the DMRV-hIBM mouse model. Nat Med 15, 690-695.

Maltais M L, Desroches J, Dionne I J (2009): Changes in muscle mass and strength after menopause. J Musculoskelet Neuronal Interact $\underline{9}, 186--197$

Manetto V, Perry G, Tabaton M, Mulvihill P, Fried V A, Smith H T, Gambetti P, Autilio-Gambetti L (1988): Ubiquitin is associated with abnormal cytoplasmic filaments characteristic of neurodegenerative diseases. Proc Natl Acad Sci U S A $\underline{85}, 4501-4505$.

Martinsson T, Oldfors A, Darin N, Berg K, Tajsharghi H, Kyllerman M, Wahlstrom J (2000): Autosomal dominant myopathy: missense mutation (Glu-706 --> Lys) in the myosin heavy chain Ila gene. Proc Natl Acad Sci U S A 97, 14614-14619. 
Mirabella M, Alvarez R B, Bilak M, Engel W K, Askanas V (1996): Difference in expression of phosphorylated tau epitopes between sporadic inclusion-body myositis and hereditary inclusion-body myopathies. J Neuropathol Exp Neurol $\underline{55}$, 774-786.

Mitrani-Rosenbaum S, Argov Z, Blumenfeld A, Seidman C E, Seidman J G (1996): Hereditary inclusion body myopathy maps to chromosome 9p1-q1 Hum Mol Genet $\underline{5}$, 159-163.

Muth I E, Barthel K, Bähr M, Dalakas M C, Schmidt J (2009): Proinflammatory cell stress in sporadic inclusion body myositis muscle: overexpression of alphaB-crystallin is associated with amyloid precursor protein and accumulation of beta-amyloid. $\mathrm{J}$ Neurol Neurosurg Psychiatry $\underline{\text { 80, }}$ 1344-1349.

Needham M, Mastaglia F L (2008): Sporadic inclusion body myositis: a continuing puzzle. Neuromuscul Disord 18, 6-16.

Needham M, Mastaglia F L, Garlepp M J(2007): Genetics of inclusion-body myositis. Muscle Nerve $\underline{35}$, 549--561.

Nemunaitis G, Maples P B, Jay C, Gahl W A, Huizing M, Poling J, Tong A W, Phadke A P, Pappen B O, Bedell C et al. (2010): Hereditary inclusion body myopathy: single patient response to GNE gene Lipoplex therapy. J Gene Med 12, 403-412.

Nishino I, Noguchi S, Murayama K, Driss A, Sugie K, Oya Y, Nagata T, Chida K, Takahashi T, Takusa $Y$ et al. (2002): Distal myopathy with rimmed vacuoles is allelic to hereditary inclusion body myopathy Neurology $\underline{59}, 1689-1693$.

Nishino I, Malicdan M C V, Murayama K, Nonaka I, Hayashi Y K, Noguchi S (2005): Molecular pathomechanism of distal myopathy with rimmed vacuoles. Acta Myol $\underline{24}$, 80-83.

Nogalska A, Engel W K, Askanas V (2010): Increased BACE1 mRNA and noncoding BACE1-antisense transcript in sporadic inclusion-body myositis muscle fiberspossibly caused by endoplasmic reticulum stress. Neurosci Lett $\underline{474}$, 140-143.

Noguchi S, Keira Y, Murayama K, Ogawa M, Fujita M, Kawahara G, Oya Y, Imazawa M, Goto Y-I, Hayashi Y K et al. (2004): Reduction of UDP-N-acetylglucosamine 2epimerase/N-acetylmannosamine kinase activity and sialylation in distal myopathy with rimmed vacuoles. J Biol Chem $\underline{279}, 11402-11407$.

Nonaka I (1999): Distal myopathies. Curr Opin Neurol 12, 493-499.

Nonaka I, Sunohara N, Ishiura S, Satoyoshi E (1981): Familial distal myopathy with

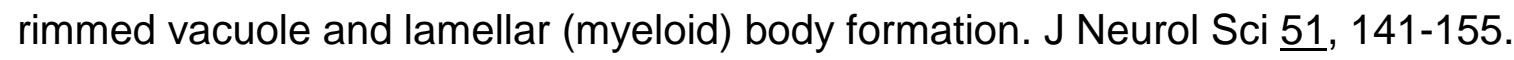

Nonaka I, Noguchi S, Nishino I (2005): Distal myopathy with rimmed vacuoles and hereditary inclusion body myopathy. Curr Neurol Neurosci Rep $\underline{5}, 61-65$. 
Raju R, Vasconcelos O, Granger R, Dalakas M C (2003): Expression of IFN-gammainducible chemokines in inclusion body myositis. J Neuroimmunol 141, 125-131.

Reinecker H C, Steffen M, Witthoeft T, Pflueger I, Schreiber S, MacDermott R P, Raedler A (1993): Enhanced secretion of tumour necrosis factor-alpha, IL-6, and IL-1 beta by isolated lamina propria mononuclear cells from patients with ulcerative colitis and Crohn's disease. Clin Exp Immunol 94, 174-181.

Ricci E, Broccolini A, Gidaro T, Morosetti R, Gliubizzi C, Frusciante R, Di Lella G M, Tonali P A, Mirabella M (2006): NCAM is hyposialylated in hereditary inclusion body myopathy due to GNE mutations Neurology $\underline{66}, 755-758$.

Sadeh M, Gadoth N, Hadar H, Ben-David E (1993): Vacuolar myopathy sparing the quadriceps. Brain $\underline{116}, 217-232$.

Saito F, Tomimitsu H, Arai K, Nakai S, Kanda T, Shimizu T, Mizusawa H, Matsumura K (2004): A Japanese patient with distal myopathy with rimmed vacuoles: missense mutations in the epimerase domain of the UDP-N-acetylglucosamine 2-epimerase/Nacetylmannosamine kinase (GNE) gene accompanied by hyposialylation of skeletal muscle glycoproteins. Neuromuscul Disord 14, 158-161.

Salama I, Hinderlich S, Shlomai Z, Eisenberg I, Krause S, Yarema K, Argov Z, Lochmuller H, Reutter W, Dabby R et al. (2005): No overall hyposialylation in hereditary inclusion body myopathy myoblasts carrying the homozygous M712T GNE mutation. Biochem Biophys Res Commun 328, 221-226.

Schmidt J, Barthel K, Wrede A, Salajegheh M, Bähr M, Dalakas M C (2008): Interrelation of inflammation and APP in sIBM: IL-1 beta induces accumulation of beta-amyloid in skeletal muscle. Brain 131, 1228-1240.

Schwarzkopf M, Knobeloch K-P, Rohde E, Hinderlich S, Wiechens N, Lucka L, Horak I, Reutter W, Horstkorte R (2002): Sialylation is essential for early development in mice. Proc Natl Acad Sci U S A 99, 5267-5270.

Sparks S, Rakocevic G, Galen J, Manoli I, Shrader J, Harris-Love M, Sonies B, Ciccone C, Dorward H, Krasnewich D et al. (2007): Intravenous immune globulin in hereditary inclusion body myopathy: a pilot study. BMC Neurol $\underline{7,1-13}$

Stober A, Aleo A, Kuhl V, Bornemann A, Walter M C, Lochmüller $\mathrm{H}$, Lindner A, Krause $S$ (2010): Novel missense mutation p.A310P in the GNE gene in autosomalrecessive hereditary inclusion-body myopathy/distal myopathy with rimmed vacuoles in an Italian family.Neuromuscul Disord 20, $335-336$.

Turner P R, O'Connor K, Tate W P, Abraham W C (2003): Roles of amyloid precursor protein and its fragments in regulating neural activity, plasticity and memory. Prog Neurobiol $\underline{70}, 1-32$. 
Vattemi G, Engel W K, McFerrin J, Pastorino L, Buxbaum J D, Askanas V (2003): BACE1 and BACE2 in pathologic and normal human muscle. Exp Neurol 179, 150158.

Whiting D, Hsieh G, Yun J J, Banerji A, Yao W, Fishbein M C, Belperio J, Strieter R M, Bonavida B, Ardehali A (2004): Chemokine monokine induced by IFNgamma/CXC chemokine ligand 9 stimulates $\mathrm{T}$ lymphocyte proliferation and effector cytokine production $\mathrm{J}$ Immunol 172, 7417-7424.

Williams G, Brown T, Becker L, Prager M, Giroir B P (1994): Cytokine-induced expression of nitric oxide synthase in $\mathrm{C} 2 \mathrm{C} 12$ skeletal muscle myocytes. Am J Physiol 267, R1020--R1025.

Wingfield P, Payton M, Tavernier J, Barnes M, Shaw A, Rose K, Simona M G, Demczuk S, Williamson K, Dayer J M (1986): Purification and characterization of human interleukin-1 beta expressed in recombinant Escherichia coli. Eur J Biochem $\underline{160}, 491-497$.

Winter A, Bornemann A (1999): NCAM, vimentin and neonatal myosin heavy chain expression in human muscle diseases. Neuropathol Appl Neurobiol 25, 417-424.

Wojcik S, Engel W K, McFerrin J, Paciello O, Askanas V (2006): AbetaPPoverexpression and proteasome inhibition increase alphaB-crystallin in cultured human muscle: relevance to inclusion-body myositis. Neuromuscul Disord $\underline{16}, 839$ 844.

Yabe I, Higashi T, Kikuchi S, Sasaki H, Fukazawa T, Yoshida K, Tashiro K (2003): GNE mutations causing distal myopathy with rimmed vacuoles with inflammation. Neurology $\underline{61}, 384-386$.

Yang C C, Alvarez R B, Engel W K, Heller S L, Askanas V (1998): Nitric oxideinduced oxidative stress in autosomal recessive and dominant inclusion-body myopathies. Brain 121,1089-1097.

Yunis E J, Samaha F J (1971): Inclusion body myositis. Lab Invest 25, 240-248. 


\section{Danksagung}

Zum Gelingen dieser Arbeit bin ich vielen Menschen zu Dank verpflichtet, ohne die ich nie soweit gekommen wäre.

An erster Stelle möchte ich hierbei besonders Herrn PD Dr. med. Jens Schmidt für die Möglichkeit zur Erstellung dieser Arbeit, die hervorragenden Arbeitsbedingungen und die ausgezeichnete Betreuung danken.

Ebenso gilt mein besonderer Dank Frau Dr. med. Ingrid Muth und Frau Dr. rer. nat. Konstanze Barthel für Ihre unendliche Geduld und stetige Hilfsbereitschaft, mit der beide wesentlich zum Gelingen dieser Arbeit beigetragen haben.

Einen weiteren Dank richte ich an Herrn Prof. Ichizo Nishino für die Bereitstellung der hIBM-Muskelbiopsien und die hervorragende Zusammenarbeit.

Für die exzellente technische Unterstützung danke ich Frau Nicole Tasch und Frau Fatima Betül Agdas.

Ein weiterer Dank gilt Herrn Arne Wrede für die Bereitstellung von Probenmaterial. Ebenso möchte ich meinen Arbeitskollegen unserer hervorragenden Arbeitsgruppe danken, die mir immer mit nützlichen Tipps und Hilfestellungen zur Seite gestanden und durch das gute Arbeitsklima stets eine Motivation geschaffen haben. 


\section{Lebenslauf}

Mein Name ist Charlotte Viola Fischer. Ich wurde am 23.02.1987 in Velbert als einziges Kind von Roland Fischer, von Beruf Kaufmann, und Ingrid Fischer, geborene Schulz, von Beruf Sonderschulpädagogin, geboren.

Nach meiner Grundschulzeit an der Grundschule Hüserstraße in VelbertLangenberg von 1993-1997 besuchte ich für viereinhalb Jahre das Gymnasium Velbert-Langenberg und wechselte dann 2002 auf das christliche Gymnasium „B.M.V.“ in Essen-Holsterhausen. Dort erlangte ich im Sommer 2005 die Allgemeine Hochschulreife.

Seit Oktober 2005 studiere ich an der Georg-August-Universität Göttingen Humanmedizin und erlangte dort im Sommer 2007 das Physikum mit der Note Gut. Im Juli 2008 famulierte ich an der Gachon-Universität von Incheon, Süd-Korea im Fachbereich Gynäkologie und belegte dort begleitend einen Kurs in koreanischer Sprache. Im Wintersemester 2009/2010 studierte ich im Rahmen eines Auslandssemesters, organisiert durch das europäische Austauschprogramm „Erasmus“, an der Universität Bologna, Italien. Dort belegte ich einen semesterbegleitenden Kurs in italienischer Sprache und famulierte im Fachbereich der Urologie, wodurch ich einige Einblicke in das italienische Gesundheitssystem gewinnen konnte. Derzeit absolviere ich mein zweites Tertial des Praktischen Jahres in der Chirurgie in den Ammerland-Kliniken in Westerstede.

Seit Februar 2008 bin ich Mitglied in der Arbeitsgruppe Muskelimmunbiologie von PD Dr. Jens Schmidt in der Abteilung für Neurologie. Hierbei habe ich mein Hauptaugenmerk auf die Pathomechanismen der hereditären Einschlusskörpermyopathie gerichtet und die vorliegende wissenschaftliche Dissertation mit dem Thema "Molekulare Zellstressmechanismen bei der hereditären Einschlusskörpermyopathie" verfasst. Einen Teil meiner Ergebnisse konnte ich bereits auf dem XII. Internationalen Kongress für Neuromuskuläre Erkrankungen 2010 in Neapel, Italien vorstellen. Ebenso habe ich die Möglichkeit erhalten, einen Vortrag über die Ergebnisse meine Dissertation auf dem Kongress der Deutschen Gesellschaft für Neurologie im Herbst dieses Jahres in Wiesbaden zu halten. 